\title{
V.-BISLIOGRATR
}

Bielsa (Rafael): Cuesiiones jut risdiccionales: acciones y recursos. Buenos Aires, 1956, 330 págs.

Trátase en esta obra de las jurisdicciones especiales, de la acción popular y la facultad discrecional administrativa, de las demandas contenciosas y recursos jurisdiccionales contra actos administrativos del lineamiento jurídico, la Ley Feleral 18 y el recurso extraordinario, con referuncia especial a las leyes fiscales de la jurisdicción universitaria, de las demandas contra el fisco, del arbitrio judicial, analizándose conceptos jurídicos y terminología.

Por la amplitud cada día mayor de la actividad administrativa pública, tiene más exrepcional importancia cuanto se refiere a la acción jurisdiccional para el examen de la legalidad de los actus administrativos. Bien reciente está entre nosotros la publicación de la nueva Ley sobre la jurisdicción contencioso-administrativa, que en breve ha de comenzar a reyir. La afirmación del estado de derecho, de la seguridad juridica, es cada día más interesante. El profesor Bielsa contribuye al estudic de esta materia con el nuevo voiumen a gue se refiere esta nota bibliográfica, en la que uild vez más muestra su competencia.

J. G. M.

BiELSA (Rafael): Derecho administrativo. t. IV, 5." edición. Buenos Aires, 1956.

Bien conocida es la obra del profesor Bielsa, que ha tenido difusión entre nosotros. En más de una ocasión nos hemos referido a trabajos suyos, ya que el número de sus publicaciones es importante, y son bien conocidas sus tareas del seminario de Derecho público y la serie de monografías publicadas: independientemente de su gran Tratado de Derecho administrativo.

El tomo IV del mismo, a que nos referimos en esta ocasión, refiérese a materia de tanta importaricia como las del Poder de Policía, las limitaciones impuestas a la propiedad privada en interés público y de Administración fiscal.

E1 libro VI de la obra, referente al Poder de Policia, trata de la protección y limitación de la libertad personal en la esfera administrativa, comenzando por senalar la significación del orden público, el order jurídico en dicho Poder, ser̃aiando la distin- 
ción entre Policia administrativa y Policia judicial, examinando las autorizaciones y los permisos de Policia, el empleo de la fuerza, la Policia y el estado de necesidad, los recursos ordinarios y extraordinarios ccntra los actos de Policia, las penas de Policia, las medidas de seguridad, las funciones de la Policía de seguridad preventivas y represivas, la Policía sobre individuos, la Policía sobre manifestaciones colectivas, Policía de reunión y Policía de asociación, la Policía del culto, la Policía de la propiedad, la de edificios en vía pública, la Policía sanitaria, la de costumbres, la general del trabajo y la de inmigración.

El libro VII. reférese a las limitaciones a la propiedad privada regidas por el Dere:ho administrativo, examinando la naturaleza jurídica de las restricciones, su diferencia con las servidumbres, su régimen jurírico: la naturaleza jurídica de las servidumbres administrativas, la ocupación tempora!, la expropiación por causa de utilidad pública. la requisición militar y civil de bienes.

El libro VIII, contiene la materia referente a la Administración fiscal, a su definición, a sus óryanos, a los ingresos fiscales.

I.a indicación de las inaterias muestra el interés de la obra, la utilidad que ofrece para el estudio de la parte del Derecho administrativo, referente a materia de tal importancia, del Poder de Policía, tanto referente a las per- sonas, como a las cosas, y la referencia que se hace a la actividad administrativa en orden al Derecho fiscal. Una vez más se pone de relieve la competencia científica y gran laboriosidad del insigne publicista argentino.

$$
\text { J. G. M. }
$$

JaCQUIGNON (Louis): Le régime des biens des entreprises nationales.-Nota previa de ClaudeAlbert Colliard y André Mathiot. Introducción de Jean Boulouis. Paris, 1956. Dos volúmenes de 364 y 332 páginas.

Pocas obras como esta que analizamos, ofrecen motivos justifcados para prestarle la debida atención que merece. Si se tiene en cuenta la evolución que en el orden político social experimentan los Estados modernos por su acusado intervencionismo, no es menor su dedicación en la esfera político económica, en la que influyen especialmente las ideologías politicas y nuevas concepciones y sistemas en contraposición a los clásicamente establecidos. En efecto, las nacionalizaciones a que se hace referencia en los tratados de Derecho administrativo y como una de las modalidades para la realización de determinados servicios públicos, no precisaban una teoría de las mismas y su naturaleza juridica basábanla ora en el marco del derecho privado o púb!ico, cuando no se adoptaba la posición de su carácter sui generis. Como quiera 
que las nacionalizaciones suponen, de una parte, la inadecuación de un sistema anterior, que sustrae una determinada masa de bienes en un régimen juridico y que es al mismo tiempo instrumento de una construcción económica, por otro que implica el establecimiento de un nuevo régimen jurídico concebido en función de un nuevo sistema económico o político de esta misma masa de bienes, reducidas asi, a una simple transferencia, el problema de las nacionalizaciones parece que únicamente ha de girar en torno a la cuestión patrimonial y que esta solución debe dominar todo su régimen.

Sin embargo, otros aspectos han de tenerse cn cuenta también, toda vez que, como sucede en Francia, esa transferencia de bienes si hasta el momento no ha motivado una construcción de un régimen nuevo, ni la destrucción del sistema anterior, ya que en definitiva - como dice Boulouislos establecimeintos nacionalizados han sido ordenados en las categorias tradicionales, como continuadoras universales de las antiguas explotaciones capitalistas, es lo cierto que la clasificación de los bienes en de dominio público $y$ privado, es irsuficiente $y$ hay que reconocer, como expone el autor, que ante una función nueva hay que crear un derecho nuevo.

De aquí el mérito de esta aportación de Jacquignon, por su trabajo pleno de cualidades, relativo $z$ un problema cuyo interés teó- rico resuelve las cuestiones prác. ticas que se dan cotidianamente en las empresas nacionalizadas, pues miembro de una empresa de esta naturaleza, ha sabido conjugar su formación jurídica con las realidades del momento, considerando, por ello, su trabajo como la primera aportación científica que perfila y crea una teoría y sistema sobre las nacionalizaciones, realidad reciente que, como hemos indicado, justifica la primera parte de su obra «A función nueva, derecho nuevo».

Teniendo en cuenta el principio que sobre las nacionalizaciones contiene la Constitución francesa de 29 de septiembre de 1946, señala las tendencias de la doctrina y jurisprundencia del país vecino para explicar la ley de nacionalizaciones dictada para desarrollar la Constitución precitada, y considera que ni en el derecho público tradicional, ni en el privado puro, puede encontrarse la justificación; de aquí su tesis, que desarrolla distinguiendo en un derecho nuevo para los bienes, los siguientes: de dominio público stricto sensu; de dominio privado $y$ de dominio nacional. Si los primeros estaban caracterizados por el interés público o privado, en los intereses colectives justifica el carácter de los últimos, por lo que la gestión de estos requieren que los bienes de que son objeto, se regulen por un régimen determinado, por la afectación de cada uno de los muismos a una utilidad esancial. Distringue 
en esta parte preliminar las caracteristicas del establecimiento público de derecho clásico, el establecimiento comercial de derecho común y e! establecimiento nacional, comerciante público.

Para constrastar, en el desarroHo de su tesis, lo que constituye el campo de los establecimientos nacionales, con la noción de utilidad esencial, en el que surgen también intereses públicos y privados, el autor divide la obra en tres partes: la primera titulada aUtilidad esencial. Criterio de fijación de la propiedad nacional»; la segunda, "La utilidad pública y los intereses privados colaboradores de la noción de utilidad esencial» y la tercera, "De los conflictos de intereses por la naturaleza de las empresas nicionales).

En la indicada primera parte, trata de la limitación de la propiedad nacional y del régimen de la misma, y estudia los distintos criterios a seguir en cuanto al primer aspecto se refiere, al mismo tiempo que da cuenta de la jurisprudencia surgida con ocasión de las nacionalizaciones. Igualmente trata del problema de la afectación de los bienes al servicio público y la posición de la doctrina, de la legislación y jurisprudencia sobre los criterios de afectación, para referirse seguidamente a la incompatibilidad funcional de la empresa nacional y de la propiedad pública.

Es de destacar su aportación sobre la noción de propiedad en sus relaciones con la utilidad esen- cial, pues precisar quién es el titular del derecho de propiedad no es materia en la que estén de acuerdo los tratadistas franceses, planteándose las soluciones aparecidas después de las nacionalizaciones, a través de las decisiones de los Tribunales y del Consejo de Estado.

La segunda parte comprende lo relativo a la utilidad pública y el régimen del poder público, así como a los intereses privados y el derecho de la riqueza, y da cuenta de la limitación de la propiedad pública, a la vez que expuestas las características de los bienes de dominio público y las causas de su afección o desafección, señala las consecuencias que suponen estas transferencias, especialmente cuando se produce la nacionalización, presentando una sistemática en todo el conjunto de esta parte, como en su obra, que revela la utilidad e importancia del tema que da a cornocer.

Como quiera que es preciso dar existencia juridica a las empresas nacionales, las cuales, hasta ahora su figura se ha perfilado inspirándose en los caracteres de las empresas industriales o comerciales, el autor, para el perfecto encuadramiento de aquéllas, aborda el estudio de sus estatutos y de la función, en donde, ádemás, después de tratar de la renovación de determinadas instituciones juridicas, entre ellas, de la concesión, se refiere a un Estatuto original.

Al finalizar cada una de las par. tes a que nos hemos referido, el 
Sr. Jacquignon ofrece unas cor:clusiones, terminando con una conclusión general an la que justifica la existencia de un derecho nuevo, cuya función y concepto precisa, puesto que el derecho dc las nacionalizaciones no es sólo una expresión cómoda, sino una realidad, cuyos límites son los mismos de la autonomía del derecho administrativo e integrado en el derecho público económico.

Cierran esta excelente aportación varios anexos, constituídos por una copiosa bibliografía y varius indices de autores, decisiones, textos y alfabético, y analítico de materias.

Nò dudamos que esta obra para los administrativistas, así como para cuantos se interesen por el derecho fúblico en general, será de necesaria consulta, sobre todo si quiere conocer la rueva evolución del concepto de los bienes y la teoría y naturaleza de las nacionalizaciones.

S. S. N.

Vaillant (Pierre): Recueil de

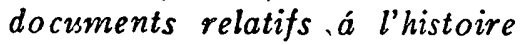
du Droit municipal en France des origines a la révolution. Les libertés des communautés dauphinoises (des origines au 5 janvier 1355). Paris, 1951, 678 páginas.

Constituye esta aportación una valiosa obra para el conocimiento de la historia del derecho municipa! sn cl páís vecino, y es el seglizido de os estudios -más arsa- plio $y$ extenso- que realiza el autcr sobre esta materia, toda vez que en el primero, llevado a cabo en el año 1934. sólo examinó el derecho de las libertades delfinesas, sin pretender saber cómo habían surgido y en qué medida crearon un derecho nuevo. En el volumer que examinamos trata de resolver este problema, merced a la abundante documentación reunida.

La importancia del temia es tanta, que el Sr. Vaillant tiene el propósito de extender sus investigaciones a las provincias vecinas del antigúo Delfinado, para confirmar y ampliar sus conclusiones.

Como fuentes ha utilizado los documentos hallados en sus investigaciones, además de las cartas que rechazó la investigadora Dillay en su Catálogo sobre Poitou y otros más que da a conocer en sus lineas preliminares y los çue se especifican en las diversas partes que preceden a la introducción, refiriéndose aquéllas : $10^{\circ} \mathrm{Al}$ repertorio de las abreviaciones utilizadas en el transcurso de la obra; $2 .^{\circ}$, Fuentes y catálogo de las cartas de exención; $3 .^{\circ}, \mathrm{Bi}$ bliografía de las obras citadas en el catálogo de las cartas; $4 .^{\circ}, \mathrm{Ca}-$ tálogo de las cartas; $5 .^{\circ}, \mathrm{Re}-$ pertorio cronológico; $6 .^{\circ}$, Indice de los títulos de franquicia concedidos por los señores, y $7 .^{\circ}, \mathrm{Bi}$ bliografía.

El excelente material reunido por el autor, to ha sistematizado para dividir su trabajo en tres partes, on la primera té :as cuales 
examina el estado de las comunidades antes de su situación de libertad, teniendo en cuenta que cuantos $d$ a tos y conclusiones aporta están enmarcadas dentro de los límites cronológicos y territoriales que imponen el numero y naturaleza de las actas catalogadas, la primera de las cuales es del año 1164 y la última de 5 de enero de 13ã ; es decir, seis después de la incorporación del Delfinado a Francia.

El autor reseña 548 documentos para 1.831 localidades, comprendidas entre las fechas citadas. Sin embargo, de la última data mencionada a 1789 , sólo se da a conocer 277 actas. Jurídicamente las cartas delfinesas se presentan como concesiones graciosas o tienen el aspecto de transacción o de sentencia arbitral.

La segunda parte se refiere al estudio de las libertades y en la misma trata de los privilegios jurídicos, fiscales, económicos y militares. En cuanto a los primeros, indica también sus límites y al hablar de los fiscales expone las prestaciones arbitrales en dinero, en especie, y las corporales, señalando también las gestiones fiscales para la comunidad y por cuenta del señor, las prestaciones extraordinarias y las ordinarias.

Entre los privilegios económicos, son de destacar las feria's y mercados a celebrar en determinadas localidades, el de poder tener moneda, el de exportar e importar, etc., $y$, entre los militares, el de la requisa, fortificar, etc.

La parte tercera está dedicada al estudio de la historia de las libertades y desarrolla el desenvolvimiento de éstas, a tenor de la política del señor en diversos territorios del Delfinado, como Embrum, Grenoble, Gap, etc., para aludir después a la organización de las mentadás demarcaciones, al frente de las cuales habia Cónsules cuyo número fué disminuyendo, los cuales podian delegar sus poderes en sindicos, contando además con una asamblea general de ciudidanos. Los Cónsules negociaban con las comunidades vecinas e interverían a título de árbitros en el nombramiento de los síndicos.

Destaca la organización de las diversas demarcaciones y termina con una serie de conclusiones, resumen del estudio de los.documentos examinados.

Por último, acompaña una serie de piezas justificativas elegidas entre antiguos textos inéditos y un mapa de las localidades comprendidas en los límites del Delfinado, en 4 de enero de $\mathbf{1 3 5 5}$.

\section{S. S. N.}

Azcortr SÁnChez-MUÑoz (Vicente) y Fernández Heras (Amado): La Ayuda familiar para los funcionarios de la Administración local. Barcelona, 1957. 62 páginas + apéndices.

Dos especialistas en la materia nos ofrecen en este opúsculo un trabajo práctico que, sin duda, ha de facilitar la tarea no sólo de las Comisiones especiales de Ayuda 
familiar, sino de las propias Corporaciones y del personal dependiente de las mismas.

La reciente implantación, por Ley de 27 de diciembre del pasado año, de la Ayuda familiar a los funcionarios de la Administración local, que hasta esa fecha carecian con carácter obligatorio de ella, forzososamente ha de plantear algunas dudas, no por lo que respecta al texto de la misma, sino en relación con aquellos a quienes se les ha de aplicar, al objeto de gozar de los beneficios que en la misma se otorgan.

A facilitar el conocimiento de lo que se dispone a los interesados, por su ámbito de aplicación, tiende este trabajo de los señores Azcoiti y Fernández Heras, los cuales, desde el punto de vista social y de la Administración local, exponen unas atinadas consideraciones, dando cuenta de cómo surgió por vez primera en nuestra Patria esta medila compensatoria y complementaria de los salarios y haberes del personal, y en la que se destaca también, el alto espiritu de algunas Corporaciones que, te antemano, establecieron esta ayuda a favor de sus funcionarios y empleados.

Ia práctica de los autores lleva a los lectores al rápido conocimiento de la Ley referenciada, mediante el resumen sistemático quie aquéllos hacen del texto legal, con lo aue muy pronto se aclaran los casos y beneficios estahlocidos.

Seguidamente, se inserta el texto integro aclarado con notas y relacionado con las disposicio nes pertinentes para justificar o precisar el alcance de cuanto se dice. Todo ello, a su vez, se ve incrementado con un extenso $y$ completo índice de materias, con referencias al artículo y párrafo correspondiente de la Ley, que permite rápidamente encontrar la materia que se desee.

Esta interesante $y$ utilísima aportación de los autores citados termina con la inserción, en un Apéndice, de las normas complementarias para la aplicación de 12 . Ley de Ayuda familiar, dictadas por la Dirección General de Administración Local, a través de diversas Circulares.

$$
\text { S. S. N. }
$$

Fourrisr (Charles): La liber té d'opinion du fonctionnaire. Prólogo de Charles Eisenmann. París, 1957, 466 págs.

La presente y extensa monografía ha sido publicada como el volumen VI de la Biblioteca de Derecho público, que desde hace poco, se viene editando bajo la dirección de Marcel Waline, y a la que ya nos hemos referido en otras ocasiones, destacando el acierto de la misma.

I a liberté d'cpinion du fonctionnaire, obra galardonada con uria subvención por el ?inisteric de Educación, es -al menos asi dice el subtituio- ur: «Ensayo de Derecho púbilico comipariado: Francia, Gran Bretafia, Estcdos 
Unidos, U. R. S. S., Alemania, Suiza, Bélgica...n. Pero, como dice el protesor Eisenmann en el prólogo, la obra es aígo más que un estudio de Derecho comparado, pues en la misma se ofrece una teoria general del problema, si bien apoyada en un análisis de las soluciones adoptadas "en un número importante de Estados. Es cierto - continúa Eisenmann- que una parte considerable de la obra está consagrada a la descripción de la situación de los funcionarios, en relación con la libertad de opinión en seis paises principalmente -Alemania, Estados Unidos, Francia, Gran Bretaña, Suiza y la Unión Soviética-; pero este análisis se hace al servicio de una empresa que la sobrepasa.

La tesis mantenida por el autor no puede ser más discutible -y discutida- Discutible por su punto de partida y por su punto de llegada. Porque, en efecto, Charles Fourrier se muestra decidido defensor de la libertad de opinión del funcionario, condenando cuantas restricciones puedan formularse al principio. Y llega, nada menos, que a la conclusión de que tal libertad de opinión resulta imposible en la sociedad capitalista, en una democracia burguesa, y que sólo es ello posible en una sociedad "socialista-marxista), en una sociedad sin clases. Naturalmente, la simple exposición del punto central de la tesis no puede por menos de sorprender. $Y$ de hecho ha sorprendido al propio prologuista, que no deja de discutir los problemas fundamintales que se abordan en la obra, aún reconociendo la honestidad intelectual del autor. "Si toda esta parte de la obra -nos dice en la página XIII - me parece, como le parecerá a un gran número de lectores, extremadamente discutible, estas grandes reservas para nada afectan a la evidente buena fe, sinceridad y lealtad de intenciones, $y$ honestidad del autorn.

Realmente, hay que reconocer que si buena parte de las conclusiones a que llega el autor, su interpretación de los hechos y la forma en que nos los presenta resultan inadmisibles, la obra es sumamente valiosa por la riqueza de datos, constituyendo un elènerito de trabajo poco menos que imprescindible para todos aquellos que se interesen por problema tan sugestivo como el de la libertad de opinión del funcionario. Pues en la monografía de Fourrier puede encontrarse, aparte de una completa exposición de la evolución de los más importantes Ordenamientos (en especial del francés), una extensa exposición de los sistemas vigentes, si hien, repetimos. dentro de la peculiar posición del autor.

Quizás, la parte más discutible de la obra sea su Título III, dedicada a estudiar lo que Fourrier llama: "Hacia la liberación del funcionarion. Fl simple enurciado de los subtítilos de esta parte revela la interición del autor.

El subtitulo I, sobre "Las luchas del funcionario francés por 
su emancipación), se divide en los siguientes capitu'os: el priwero (El movimiento emancipaJur de los funcionarios en trancir), se divide, a su vez, en tres secciones, que estudian las causas del nacimiento de! sindicálismo emancipacur, sus etapas principales y los efectos de la unión del movimiento emancipacior con el movimiento cbrero El capitulo II (sobre "El Estado reptblicano francés contra la emuncipación de los fumicionarios"), contiene una expcsición de lus jalones fundameniales de esta uluchay.

El subtítulo II trata de "La likertad actuai del funcionario fruncés y sus límiţes). Tistá dividido en cuatro capliulos, cuya lectura permite conocer la situación actual francesa, tanto en los textos legales, como en la jurisprudencia y en la doctrina.

Y el subtítulo III se dedica íntegramente a la situación del funcionario en la Unión soviética. Se divide en tres capítulos, que tratan de la "Formación de la concepción soviética de la función pública», de "Los conceptos de libertad de opinión y de funcionario en la Unión Soviética» y del "funcionario soviético».

En resumen: con las importantes reservas apuntacias, la obra resulta útil, por el aciopio de datn: para conccer (prescindiendo de la peculiar fusición del autor) 1. situación soviética sobre el problema, que Fourrier nos ofrece ut:iizando en buena parte fuentes de primera mano.

\section{J. GonzÁLEZ}

RUIZ FERnández (Francisco): Fianza colectiva y mancomunada de los Dipositarios de fondos de Admunistración local. Instituto de ristudios de Administracion Local. Madrid, 1957, 156 páginas.

Uno de los problemas más espinosos e insolubles del Cuerpo ds Depositarios de fondos de Administración local ha sidn, y es, el de las fianzas A todo funcionario se le exige una competencia profesional más o menos especializada. Al Depositario se le exige esa competencia y, además, un capital -aunque sea modestoinmovilizado, para el desempeño de sus funciones.

Ese problema, que sigue sin resolver en forma satisfactoria para todas las partes interesadas (Corporaciones, Depositarios) ha sido elegido por Ruiz Fernández como tema de su tesis en e! Curso para Jnterventores Diplomados en Adininistración local celebrado en el Instituto de Estudios de Administración Local en 1955. El Instituto, consciente del valor actual del estudio realizado, ha procedido atinadamente a su edición.

Aparte del profundo conocimitnto de estas materias por el autor - no en balde es titular de una Depositaria importante y pertenece, además, al Cuerpo de Interventores-, el trabajo revela 
un buen sentido de metodologia expositiva

La obra consta de dos partes fundamentales: una, dedicada al estudio de los aniecedentes y de las directrices que deben informar la regulación de un sistema de afianzamiento colectivo ; otra, dedicada a la articulación completa de ese sistema en un texto de apariencia normativa. Los anexos ilustran, con modelos, ejemplos y datos actualizados, la curiosidad del lector interesado.

E1 sistema propugnado por Ruiz Fernández parte del supuesto -exacto- de la heterogeneidad actual del Cuerpo de Depositarios, de la resistencia psicológica de sus componentes a integrarse en un régimen de responsabilidad solidaria con compañeros cuya personalidad y cualidades les son desconocidas, y de la necesidad, sin embargo, de evitar a esos funcionarios, y muy especialmente a los de nuevo ingreso, la dificultad -en ocasiones, casi prohibitiva- de constituir una fianza cuya cuantía, si bien hoy resulta visiblemente moderada, no está al alcance de todos los patrimonios.

Para obviar todos los posibles inconvenientes, el sistema ideado pur el autor cristaliza sustancialmente en la constitución, diversificada, de mancomunidades de Depositarios (para la constitución de cada una se exigiria un mínimo de veinte miemhros), a las cuales los mancomunados aportarian, en el momento inicial, una suma equivalente al diez por cien- to de la fianza correspondiente a la plaza que desempeñasen, $y$, en anualidades sucesivas, un tanto por ciento variable, según la edad de cada mancomunado. De cualquier alcance respondería, en primer lugar, el haber depositado perteneciente al Depositario responsable (acervo constituído por su aportación inicial, por sus aportaciones sucesivas anuales $y$ por los intereses devengados por una y otras) y luego, hasta el total de la fianza correspondiente a la plaza desempeñada por el alcanzado, la mancomunidad (el' prorrateo pasivo entre sus miembros sería proporcional a las aportaciones individuales durante el último ejercicio).

La obligatoriedad del sistema sería, para cada Depositario, sólo genérica, pues habría de integrarse forzosamente en una mancomunidad de Depositarios, pero el margen de voluntariedad sería de notable amplitud, al poder elegir su ingreso entre las diversas mancomunidades que se constituyeran (contando, naturalmente, con la voluntad de los demás mancomunados de cada una). También se prevé el caso, raro pero posible, de! Depositario que no sea admitido en ninguna mancomunidad de las. constituidas.

La articulación proyectada j:revé meticulosamente todo lo relativo a la constitución, modificación y extinción de las mancomunidades, a su régimen interno $y$ al incremento, reducción y devolución de las fianzas. Prevé asimismo, como pivote coordinador 
de todo el sistema, la constitución de una Junta Ordenadora de fianzas en la Dirección General de Administración Local.

No es este el momento, ni el lugar, para un análisis crítico del sistema propuesto. $\mathrm{Ni}$ estaríamos capacitados para hacerlo. Posiblemente sus mayores aciertos radiquen en la amplia órbita de facultades que se concede a la voluntad de cada interesato, $y$ en la utilización del Banco de España como custodio de los depósitos de las mancomunidajes de Depositarios. Posiblemente, su punto más discutido será la obligatoriedad de mancomunarse. Quizá, también se eche de menos una mayor audacia en cuanto a una mayor matización administrativa $\longrightarrow$ con la consiguiente agilidad de procedimiento- huyerıdo de formalidades civiles, siempre enojosas.

En todo caso, una vez difundida la obra resultaría de :extraordinario interés que los Colegios Oficiales y los Depositarios interesados expresasen sus opiniones, con sentido constructivo, respecto al trabajo de Ruiz Fernández, que, a nuestro entender, es, sin duda, lo más completo $y$ concienzudo que se ha elaborado en el estudio del delicado problema de las fianzas de los Depositarios.

El Director del Instituto de Estudios de Administración Local, don Carlos Ruiz del Castillo, prologa el libro con una nota preliminar, breve, precisa, sobre el sentido de la obra y el significado de los cursos de Diplomados.

A. C. C.

\section{REPERTORIO de la VIDA LOCAL DE ESPaÑa} (1956)

Legislación, Jurisprudencia, Resoluciones del Ministerio de la Gobernación y de la Dirección General de Administración Local, Dictámenes del Instituto, Estadistica y Nomenclátor de cargos de la Administración local.

Un tomo en tela con 1 roo páginas.

Precio: 350 pesetes.

PEDIDOS :

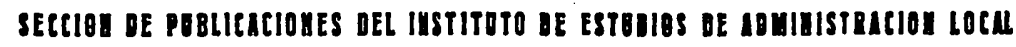

J. Garcla Morato, 7. Tzlktono 2337 03. Madrid. 


\section{VI-REVISTA DE REVISTAS}

\section{a) ESPANA:}

\section{a) REVISTAS DE REGIAEEN LOCAL}

\section{Boletin del Colegio Nacional de Secretarios, Interventores y Depositarios de la Adminis- tración Local}

Madrid.

Marzo 1957.

Núm. 147.

Exrracto: Nota que, como consecuencia de la última reunión de la Junta de Gob:erno del Colegio Nacional, celebrada el día 21 de marzo de 1957, se publica en el aBoletín Oficial del Colegios, a fin de que los colegiados conozcan la actuación de la Junta en orden a la tabla de méritos de los concursos.-La figura del Director general, D. José García Hernández (V. Balbín Pechuán).-Influencia del régimen juridico local en la nueva Ley de to Contencioso-Admin strativo (J. Gascón y Marín).-Algunas consideraciones sobre el nuevo baremo (V. Balbín Pechuán).-La nueva política local y el Servicio Nacional de Inspección y Asesoramiento (A. Saura Pacheco).Vida profesional. - Not cias.-Circula res de la Dirección General de Administración Local.-Crónica legislativa (A. de la Rica y Arenal).

Influencia del régimen juridico local en la nueva Ley de lo Contencioso-Admivistrativo, por $\mathrm{J}$. Gascón y Marín.

La nueva Ley reguladora de la jurisd:cción Contencioso-Administrativa de 27 de diciembre de 1956 ha suscitado, por su gran importancia, comentarios de nuestros tratadistas. Merece destacarse ol trabajo publicado por el profesor Gas- cón y Marín en el eBoletín del Colegio Nac:onal de Secretarios, Interventores $\boldsymbol{g}$ Depositarios de la Administración Locals. Afirma el profesor Gascón y Marin que la materia contencioso-administrativa durante los años transcurridos desde 1924, con la publicac:ón del Estatuto Municipal, hasta la promulgación de la nueva Ley de 27 de diciembre de 1956, ha ofrecido' la singularidad de tener mayor amplitud en la esfera local que en la de la Administración General del Estado. El texto refundido de 1952 lo acredita con claridad, al disponer el artículo $1 .^{\circ}$ que en materia provincial y municipal podrá interponerse, además del recurso corr:entemente denominado de plena jurisdicción, contra la resolución que cause estado, emane de facultades regladas de la Administración y vulnere-dereclio de carácter administrativo establecido anteriormente en favor del demandante por una Ley, un Reglamento $u$ otro precepto adm;nistrativo, recurso de anulación por incompetencia, vicio de forma - cualquier otra vulneración de leyes o disposiciones administrativas, siempre que el recurrente tenga un interés directo en el asunto.

Análogo estudio se realiza en lo que se refiere a la materia contenc:osa en el Estatuto Municipal y en la ILey Municipal de 1935. Destaca el maestro Gascón y Marín que la nueva Ley ha recogido principios contenidos en las disposic:ones referentes a régimen jurídico de la Administración local, pues el artículo $\mathbf{4 1}$ admite el que pueda pretenderse ante la jur:sdicción contenciosa la declaración de no ser conformes a Derecho, y en su caso, la anulación de los actos y disposiciones susceptibles de impugnación, y conforme al artículo 28, al pretender el reconocimiento de una situación juridica individualizada, la adopción de medidas para el pleno restablecimiento de la mis. ma, incluso indemnización de daños perjuicios cuando proceda.

Las disposiciones sobre régimen juridico de las entidades locales han venido 
exigiendo a partir del. Estatuto de 1924 la interposición del recurso de reposición contra la aecisión o acuerdo que se impugna antes de poder interponer el recurso contencioso-administrativo. La nueva Ley, en $\mathrm{su}$ artículo 52 , como requisito previo para interposición de. este recurso, dispone que deberá formularse recurso de reposición exponiendo los motivos en que se funda. Se exceptúa únicamente, según el articulo 53, los actos que impl quen resolución de cualquier recurso adm.nistrativo, incluso el economico; los dictados en ejercicio de la potestad de fiscalización, si fuera aprobatorio del acto fiscalizado; los actos no manifestados por escrito y las dispos:ciones de carácter general no aprobadas definitivamente en vía administrativa. Se destacan tambièn en el artículo que comentamos los problemas del silencio administrativo, de procedimientos especiales $y$ otros.

A. D. $P$.

Abril 1857.

Núm. 149.

Extracto: Los nuevos sueldos de los funcionarios de la Administración local.-Aspiraciones: Carta ab erta a los compañeros de los Cuerpos Nacionales (V. Balbín Pechuán). - Realidades y perspectivas de la reforma local (J. Garcia Hernández).-El Servicio Nacional de Inspección y Asesoramiento (M. Ruiz Esteller).-El recurso de reposición en la nueva Ley reguladora de la jurisdicción Contencioso-Administrativa (A. de la Orden Dominguez). Vida profesional. - Noticias.-Crónica legislativa (A. de la Rica y Arenal).Presupuestos de gastos del Estado para el ejercicio de 1957 .

El recurso de reposición en la nuseva Ley reguladora de la jurisdicción Contencioso-Administrativa, por $\mathrm{A}$. de la Orden Dominguez.

El trabajo comienza afirmando que no se trata de construis en el mismo una teoría general del recurso de reposición, sino de destacar el único punto del nuevo ordenamiento de la jurisdicción Contencioso-Administrativa que no ha lograco satisfacer de modo pleno al autor, añadiéndose que no se trata de señalar defectos, ples son kanios los aciertos de la ley cute quizá el mejor tributo-äice Is Crcis-q:as jueda rendirsele sea re- flejar las dificultades que se encuentrar para lograr algún punio crit.cable.

Considera el autor que del estudio de! preámbulo de la Ley, y por el lugar en que se encuentra encuadrado el recurso de reposición, pudiera inducirse que los redactores de la misma han querido considerar el mentado recurso como mero requisito o trámite previo, dada la posición desde que contemplaban tal insticuto al tratar de configurarlo con vistas al desenvolvimiento de una actividad puramente jurisdiccional; mas no obstante esa acusada preocupación, es evidente que el susodicho recurso, al hacerlo obligatorio, sigue ofreciendo en la nueva Ley el mismo matiz de ambivalencia que le venia caracterizando en el régimen -jurídico privativo de las Entidades locales: recurso administrativo que prolonga y cierra la vía administrativa cuando en ésta no es posible la alzada, y trámite previo indispensable para que pueda ser efectuada la revisión del acto por el órgano jurisdiccional, ya que no creemos que pueda ofrecer duda alguna la posibilidad de que cualquier particular afectado en su derecho por un acto admin:strativo y que no pretenda interponer contra él recurso contencioso-administrativo, utilice, no obstante, el recurso de reposición, con ánimo solamente de agotar todo orden de razonam ento y fundamen. tación en via administrátiva para ver de lograr, en un último intento, la rectificación de la manifestación volitiva del órgano que lo dictó. Enirando a fondo en el estudio del problema del recurso de reposición, considera el autor del trabajo, que contemos que el mismo, tanto para el recurrente, como para la Admiristración, tendrá todos los efectos inherentes a su naturaleza de recurso admin:strativo y pone de relieve que el primer problema que habrá de planteársele a! sujeto que resulte lesionado en su derecho o interés legítimo por un acto de la Administración, será el de la deterıninación de si tal acto es o no susceptible de recurso de reposición, pues si cree que éste es preceptivo a los efectos de im: pugnación de aquél ante la jurisdicción contencioso-administrativa, y, por sufrir error en esa apriorística catalogación, resulta luego no serlo, puede quedar cercenada la posibilidad de revisión jurisdiccional del acto administrativo, si, confiado en el amplio plazo que el párrafo 2) del aríiculo 5.9 de la Iey, le ofrece en ei supuesto de inexistencia de resa lución expresa, no interpusiere el recursc 
contencioso-admiristrativo dentro de los dos meses çia se previenen en el apartado 3), letra a) del mismo articulo c:tado, ya que a ienor de las prescripciones contenidas en los articulos 62 , letra d) del párrafo 1), y 82, letra f), la interposición del recurso contencioso-administrativo fuera de plazo, obliga al Tr.bunal a que declare ineludiblemente la inadmisibilidad del mismo.

Tras estas afirmaciones estima el articulista que todo ello podria haberse evitado si en vez de instituir el recurso de reposición con carácter de requisito previo o trámite indispensable, se le hubiera declarado potestativo, reconoc.endo de modo expreso a los órganos de la Administración, facultad suficiente para poder revocar o reformar, e incluso sustituir, todos sus actos, aunque fueren declarativos de derechos, antes de contestar la demanda, cuando hubiesen sido impugnados ante la jurisdicción contencioso-administrativa sin haber utilizado el demandante el recurso de reposición, pues, al ser potestativo éste, la necesidad de establecer actos exceptuados de la reposic.ón, hubiera desaparecido, y con ella, la dificultad que supone para los administrados esa apriorística determinación del acto, y el peligro que puede representar para la salvaguardia de los derechos de aquéllos el error sufrido al verificar esa catalogación si consideran exceptuados del recurso de reposición actos que en realidad no lo estuvieren a juicio del órgano jurisdiccional; quedando, en cambio, asegurado ei logro de los fines persegudos por la Ley, al instituir el recurso de reposición como requisito previo, ya que el administrado podria, siempre que quisiera, intentar la evitación del proceso, tratando de convencer al órgano administrativo con sus argumentos $y$ alegaciones mediante la interposición de d cho recurso, y la Administración, al propio tiempo, si lo reconocia justo, podría acceder a las pretensiones del demandante, sin neces dad de contender en via judicial, al conocer los fundamentos de aquéllas cuando le fuere dado traslado de la demanda, en los casos en que no hubiere sido formulada la reposición, añadiendo a continuación el autor, que no hab endo sido ésta la fórmula adoptada por la liey se impone la observancia de un especial cuidado al verificar la clasificación del acto administrative a efectos de reposición para no dar lugar a la caducidad de já acción contencioso administrativa.
Acto saguico se ser̃aian águnos casos xácicos para poner de rel.eve el punto cie vista sostenido por el autor del trabajo que comentamos, que termina $\cos$ las siguientes palabras: a $E_{n}$ resumen, que creemos que la institución del recurso de reposición no alcanza en la Ley e! grado de pr:morosidad técnico-cientifica que toda la estructuración y conformación de la misma ofrece, por lo que, quizá merezca la pena que plumas nás autorizadas se ocupen del problema, por si aún es posible eritar que un recurso administrativo quede desnatural:zado en cierto modo, at dejarlo equiparado a cualquier otro simple requisito c presupuesto de carácter formal de los que pueden ser subsanados en todo momento dentro del-procesos.

A. D. P.

\section{Certamen}

Madrid.

13 abril 1057.

Núm. 127.

Extracto: La nueva política local y el Servicio Nacional de Inspección y Asesoramiento.-Noticiario profesional y de $j_{a}$ vida local.-Técnica politica y Administración (P. Sánchez Moreno).La $\tan$ debatida cuestión de los limites de población y las Secretarias (F. Llopis Planell).-El Secretario de Administración Local y los Juzgados de $\mathrm{Paz}$ (M. Aguado Morillas).

30 abril 1957.

Núm. 128.

Extracto: La efectividad del derecho a disfrutar licencia (E. Barros).- Deontologia profesional (P. Sulleiro).

\section{E1 Consultor de los Aynn- tamientos}

Madrid.

10 abril 1957.

Núm. :0.

Extracto: Empleados de-Administración local: valoraciones en concursos.

20 abril 1957.

Núm. 11.

Exrracto: Contratos munic pales: revisión de precios.-Archivos: remisión de copias de inventarios. 
80 abril 1957.

Extracto: Reemplazos: prórrogas de segunda clase.-La formación profesional de los Secretarios de Administración Local (M. V. Meruendano).

10 mayo 1957.

Nủm. 13.

Extracto: Empleados de Administración local: nuevos sueldos mínimos.Turismo: normas para su propaganda.

\section{E1 Secretariado Navarro}

Pamplona.

6 abril 1957.

Núm. 2.697.

Extracto: Arrendamientos urbanos.Beneficios a refugiados o apátridas.Mod:ficación del sistema general disciplinario de empleados municipales.

14 abril 1957.

Núm. 2.638.

Extracto: Contribuciones e Impuestos en Niavarra (M. Maria Troncoso).

21 abril 1957.

Ním. 2.609.

Extracto: Viviendas de renća limitada.

28 abril 1957.

Núm. 2.700.

Extracto: La Ayuda familiar: el artículo 26 del Reglamento.

6 mayo 1957.

Núm. 2.701.

Extracto: El Decreto Ley señalando sueldos minimos a los funcionarios de Administración local.

14 mayo 1957.

Núm. 2.702.

Extracto: El proyecto de Ley del Registro civil.

21 mayo 1957.

Nủm. 2.703.

Extracto: El documento nacional de identidad.-Normas para la práctica del acampamento turístico en España.
Barcelona.

Abril y mayo.

Nủms. 76 y 77.

Extracto: Las oficinas de la Comunidad Europea de Crédito Municipal inauguradas en Turin (L. G. Marqués Canós).-Andanzas de un municipalis. ta por tierras de España: en el Archipiélago canario (L. Marqués Carbó).

\section{La Administración Práctica}

Barcelona.

Abril 1957.

Núm. 4.

Extracto: Cuentas municipales en 1956 : expediente de examen, censura y aprobación de las cuentas municipales del ejercicio de 1956.-Contratación de las Corporaciones locales: revis ón de precios en obras ejecutadas.-Funcionarios de Administración local: ayuda familiar a las clases pasivas.-Procedimientos administrativos: jur sdicción rogada (A. Carmona).-Jurisdicción contencioso administrat va: consideraciones sobre la nueva iLey (F. Pujol Germá).-Sucinta referencia a la cesión de terrenos regulada por la Ley del suelo (E. Ferrerons Reñé).

Mayo 1957.

Nừm. 5 .

Extracto: Instrucción Pública: casas municipales de cultura.-Su creación $Y$ funcionamiento.- Nueva ordenación del Boletín Oficial del Estado.

\section{Municipalía}

Madrid.

Marzo 1957.

Núm. 50.

Extracto: La nueva política locai y el Servicio Nacional de Inspección y Asesoramiento (A. Saura Pacheco).-Defensa de los bienes del patrimonio municipal (L. Navarro Harriba).-Servicios municipales potestativos (A. Gallego Burín).-El cargo de Secretario 
en la legislación local comparada ( $P$. Dávila Carrizosa).

Abril 1957.

Núm. 51.

Exrracto: Filadelfia, la aristocrática (L. G. Marqués Canós).

\section{Policia Mnnicipal}

Madrid.

Marzo 1957.

Núm. 108.

Extracto: Tráfico y urbanismo (A. Ga llego y Burín).-Aqui la Policia Municipal de Madrid (M. Illera).

\section{Revista Moderna de Administra- ción Local}

\section{Madrid.}

Abril 1957.

Núm. 552.

Extracto: Impuesto Municipal de Plus Valia. Una trascendental sentencia del Tribunal Suprem. (F. Sans Buigas).- La Ayuda fam liar extensiva a las clases pasivas de la. Administración local y a los Cuerpos sanitarios (V. Vázquez Galván).-Glosas municipales.

Impuesto Municipal de Plus Valía. Uno trascendental sentencia del Tribunal Supremo, por F. Sans Buigas.

El articulo que glosamos tiene su origen en que al Ayuntamiento de Esplugas de Llobregat le fué impugnada una liquidación del Arbitrio sobre el incremento del valor de los terrenos, reclamac:ón que se interpuso ante el Tribunal Económico Administrativo Provincial, cuyo acuerdo fué reclamado por la Corporación ante el Tribunal Contencioso Admi$n$ istrativo de Barcelona, y cuya sentencia también fué apelada ante el Tribunal Supremo. Entre otros aspectos se plantean en esta Sentencia los problemas siguientes :

1. Liquidación del arbitrio en trans. mis ones de dominio operadas dentro de la vigencia de una misma tabla trienal.

2. Facultad de atenerse en todas las liquidaciones al precio escriturado en las dos transmisiones que inician y cierran el periodo impositivo de cada transmisión.

3. Improcedencia de deducciones de la cuota liquidada en relación con la durac:ón del periodo impositivo.

4. Cómputo en las liquidaciones de los terrenos viales simplemente afectados por planos de urbanización.

5. No limitación del arbitrio sólo a los terrenos que reúnen la condición de solar.

La sentencia del Supremo, fecha 10 de diciembre pasado, contiene los siguientes pronunciamientos que a continuación transcribimos por ser de gran interés para nuestros lectores:

1. Que para la determinación de la cuantia del arbitrio municipal a que esta sentencia se refiere, el Ayuntamiento de Esplugas de Llobregat pudo tomar en cuenta, como lo hizo, los valores consignados en las escrituras públicas correspondientes a que también alude.

2.0 Que no procede deducir de la cuota tributaria respectiva cantidad alguna, con relación al tiempo del periodo impositivo, $y$

3. Que han de ser objeto de la imposic:ón del indicado arbitrio de Plus Valia las superficies de los terrenos de que se trata, destinados a vías públicas de dicha población.

Los fundamentos en que se apoya el fallo dicho, vienen contenidos en tres considerandos dictados con vistas: al Decreto sobre ordenación de las $\mathrm{Ha}$ ciendas Locales de 25 de enero de 1946 ; a: Reglamento de Procedimiento en las reclamaciones económico-administrativas de 29 de julio de 1924; al Decreto de Texto refundido de la jurisdicción contencioso-administrativa de 8 de febrero de 1952, y a las sentencias del propio Tribunal de 12 de mayo de 1952 y 21 de enero de 1953.

Consideramos, por tanto, dice Sans Buigas, que con esta sentencia se fija claramente el ámbito del arbitrio en cuanto al objeto del mismo, declarándose que lis condición de ser solar un terreno, para que pueda, a su vez, ser objeto de dicha aplicación, no constituye una norma general, sino tan sólo una limitación del privilegio que tienen los terrenos que son explotaciones agricolas; forestales, ganaderas o mineras.

A. D. P. 


\section{San Jorge}

Barcelona.

Abril 1957 .

Núm. 28

Extracto: La espada en ios siglos $\mathbf{x v}$ y XVI (J. E. Cirlot). - Treinca años de carillón (J. Tarin-Iglesias).-Justas y torneos en las fiestas de San Jorge (E. Cubas Oliver).-El extraordinario yacimiento prehistórico de Moyá (J. de C. Serra y Rafols).-Hospital comarcal de Vich: notas históricas (F. Serra). - Ante el dia de la Provincia de 1957 (C. Font Llorpart). - El Condado norteimericano (L. G. Marqués Canós).

El Condado norteamericano, por L. G. Marqués Canós.

A juicio del autor del artículo que comentamos el Condado es la unidad local norteamericana más parecida a la provincia española.

Marqués Canós dice textualmente: - Resulta difícil dar una definición exacta del Condado tal como existe en Norteamér.ca, pero puede decirse que, en general, es una división del territorio del Estado creada para servir a los fines generales del mismo. Se trata, pues, de una subdivisión de carácter territorial, y la suma total de las áreas de los Condados de cada Estado es (las más de las veces, pero no necesariamente) igual al área del mismon.

Al hablar de la clasiflcación de los Condados dice que hay quien los clasifica entre las Entidades locales, mientras hay quien lo define como una criatura estatal ę: función de órgano descèntralizador del Estado. El Condado, en efecto, fué la primera subdivisión administrativa del Estado, creada para prestar algún servicio público principal, como: seguridad pública, la Corte judicial, escuelas y carreteras de la circunscripción. Hay que señalar que el Condado no t:ene ningún poder regulador, limitándose a aplicar la legislación estatal en el propio territorio. Realmente en cuarenta y ocho Estados norteamericanos el Condado existe como unidad administrativa. Las dos excepciones son: el Estado de Rhode Island que no posee ningún Condado y el de Louisiana en el que la subdivisión administrativa equivalente al Condado se denomina eparihss.
Continúa Marqués Canós su detenido estudio subre el Condsdo norteamericano y afirma que la importancia del Condado como unidad administrativa $y$ de gobierno puibl co varia en los diferentes Estados. En ios del Sur y Oeste del país es la unidad básica. del gobierno lucal. En los del Noroeste y Centro-norte $s_{i}$ acción se ve completamente por la del atown y el atownship». En Nueva Inglaterra, es decir, cl- Nordeste, la unidad básica del gobierno es el atowns, mientras que en el Condado tiene importancia secundaria, añadiendo que la verdadera importancia del Condado es de tipo político. En vez de ser una mera división adininistrativa, su funcionamiento está intimamente relacionado con organizaciones politicas locales que, a su vez, son delegaciones de organizaciones polít:cas superiores. $Y$ quien controla los Condados, controla el Estado.

A continuación transcribimos íntegramente las funciones que a juicio de Marqués Canós tiene el Condado norteamericano:

1. Participación en la Administración de justicia, por medio de Tribunales integrados en el sistema judicial del Estado. Estos Tribunales están financiados con fondos del Condado, servidos por el sheriff y otras autoridades y funcionarios del Condado, y dirigidos por jueces, generalmente elegidos por electores del Condado.

2. Vigilancia del cumplimiento de las leyes penales del Estado, por medio de las oficinas del eprosecuting attorneys (fiscal), del sheriff y del coroner.

3. Mantenimiento de una cárcel del Condado (generalmente a cargo del «sheriff $p)$, para el encarcelamiento de personas en espera de ser juzgadas y de los condenados a penas de corta duración.

4. Administración de la función de libertad bajo palabra.

5. Registro de escrituras, hipotecas, testamentos y otros documentos.

6. Valoración de propiedades sujetas a imposición, recaudación de impuestos y custodia de fondos.

7. Exped ción de licencias de matrimonio, de caza, de pesca, etc.

8. Administración de ciertos servicios de sanidad pública en las zonas rurales.

9. Prestación de servicios de beno ficencia.

10. Actividades de educación, a veces de simple supervisión y en ocasiones 
de mantenimiento y controi directos de escuelas rurales.

11. Construcción y conservación de diversas obras públicas, especialmente carreteras secundarias, pueittes, sistemas ae drenaje y edificios públicos; y

12. Administración de elecciones, con inclusión de las siguientes actividades: preparación de papeletas electorales, selección de locales, nombramiento de funcionarios electorales y escrutinio de los votos.

Las funciones enumeradas hasta ahora son las que podriamos llamar etradicionaless del Condado, es decir, aquellas que desempeña en calidad de delegado del Estado. Por lo que respecta a las nuevas funciones del Condado, su diversidad es aún mayor, pero podemos consignar las siguientes: mantenimiento de parques, terrenos de recreo y otras instalaciones similares; establecimiento y administración de b:bliotecas públicas; administración de hospitales; construcción y mantenimiento de aeropuertos; prevención de incendios forestales; prestación del servicio de bomberos; construcción y administración de sistemas de abastecimiento de aguas y alcantarillado; distribuc:ón de electricidad; construcción de viviendas de renta barata; planeamiento, y actividades varias relativas a agriculturá y conservación de recursos naturalesi.

\section{A. D. P.}

\section{Villa de Madrid}

Mayo 1957 .

Año I, núm. 1.

Llega a la mesa de nuestra Redacción. e! número primero de la revista QVilla de Madridn, interesante publicación del Ayuntamiento de la Capital de España, realizada bajo los auspicios del aCentro de Estudios Municipales Antonio Mauran.

Este rúmero está especialmente dedicado a S. E. el Generalísimo Franco, al que el Ayuntamiento de Madrid, con su lealtad rendida, of rece el primer número de su revista al que siempre supo marchar fiel y acertadamente a la cabeza de nuestros destinos.

La revista aVilla de Madridø se honra publicando una magnifica fotografía de Su Excelencia el Jefe del Estado, dedicada a la expresada publicación.

- Villa de Madrido comienza su texto con un saludo del Conde de Mayalde,
Alcalde del Ayuntamiento madrileão, que por su interés transcribimos: eDesđe hoy, el Ayuntamiento de Madrid posee voz propia a través de su revista. Durante muchos años el Ayuntamiento debió tomar prestadas otras voces para comunicar con aquellos que dependian, directa y entrañablemente, de él: con los madrileños. Ahora, cuando a través de la revista aVilla de Madrido toma contacto directo con los que integran su Municipio, quiero expresar mi agradecimiento a la Prensa, en primer lugar, a la radio y a todas las manifestaciones del conocimiento que, durante ànos, nos sirvieron de enlace cordial con nuestro pueblo.

aVilla de Madrido pretende recoger la ilusión, la historia y los afanes de los madrileños. Como Alcalde, soy el más llamado a su servicio, y desde aquí quierc enviar a todos mi saludo. Que ello sirva para expresar a Madrid, de todo corazón, el cariño y la preocupación de sus administradores. El afán de realizar la gran Ciudad que sueña Franco y que, con la ayuda de Dios, hemos de lograrp.

El propósito de la revista Villa de Madrido es que sea exponente de realizaciones, proyectos e ilusiones del Ayuntamiento madrileño. Sus páginas, según se dice en el editorial; se encontrarán abiertas para todos los que, con buenas intenciones, deseen ejercitar una critica sobre la labor que realiza la Corporación, sugerir proyectos o ideas. También es propósito de la revista hacer de Madrid una gran capital; modernizar sus vias, acercar sus suburbios, extender su perimetro, dar nuevo paisaje a muchos de sus alrededores faltos de él, no es, en última instancia, otra cosa que servir a la espiritualidad de Madrid; como adornar una belleza, o hacer feliz una vida, es también una manera de servirlas.

Para que nuestros lectores tengan una idea de la extraordinaria importancia de esta nueva publicación, a continuación damos el sumario:

Dedicatoria.

Saludo, por José Finat y Escrivá de Romani, Conde de Mayalde.

Editorial.

El Dos de Mayo.

El Retiro, por Agustín de Foxá, Conde de Foxá.

Madrid de ayer, por Mesonero Romanos.

Madrid de hoy, por Manuel Pombo Angulo. 
Madrid de mañana.

Poemas de Madrid, por Gerardo

Diego.

Poemas de Madrid, por Lope de Vega.

Arte, por José Camón Aznar.

Arqueologia, por Julio M. Santaolalla.

Teatro, por Alfredo Marquerie.

Cultura, por José Maria Soler.

Deporte.

Vida corporativa.

Puerta del Sol.

Enseñanza, por José M.a Gutiérrez del Castillo.

¿Qué le gusta más de Madrid?, por

Vicente Carredano.

Bibliografia, por J. Leal Fuertes.

Piso Bajo, novela inédita, por Ramón Gómez de la Serna.

Dibujos: Serny.

Fotografias: Loygorri.

La revista está, como ya nos tiene acostumbrados el Ayuntamiento madrilefoo, magnificamente editada, con un papel excelente y muy buenas fotografias, que hacen de ella, aparte de su singular contenido, una publicación de lectura fácil y amena.

Saludamos a la nueva publicación, a la que deseamos muchos aciertos, y felicitamos al Excmo. Ayuntamiento de Madrid, en la persona de su Alcalde, el señor Conde de Mayalde, por este nuevo éxito que pone de relieve el interés del Ayuntamiento de la capital de España por los problemas locales.

\section{A. D. P.}

b') REVISTAS DE LOS CENTROS DE INVESTIGACION Y ESTUDIOS LOCALES

\section{Altamira}

Santander.

1956.

Núms. 1, 2 y 3.

Extracto: La noticia de la muerte de Menéndez y Pelayo en las Cortes y en la Prensa nacional (L. Redonet).Un elogio de Menéndez y Pelayo del que fué ilustre cronista de la ciudad de Sevilla, D. Luis Montoto.-Adiciones y notas a la bibliografía de $\mathrm{Me}$ néndez y Pelayo ( $T$. Maza Solano).Un centenario: 1856-1956. El descubrimiento gcográfico de los Picos de Europa.-Exvotos marineros en Santuarios santanderinos (F. Barreda).

\section{Argensola}

Huesca.

4. ${ }^{\circ}$ trim. 1956.

Núm. 28.

Extracto: Cooperación universitaria de los Ayuntamientos (S. M.-Retortillo). Tamarite y San Esteban de Litera a cambio de Albarracin. (Unos documentos importantes para la historia de. Aragón) (A. Gutiérrez de Velasco).-San José de Calasanz, hijo de Peralta de la Sal (J. Poch).

\section{Cooperación universitaria de los Ayum} tamientos, por S. M. Retortillo.

Este problema, más que político, no es sino un problema que entraña una complejidad de matices, entre los que los juridicos y humanos tenen relevancia importante: es la necesidad de asegurar una igualdad de condiciones en un ambiente de desigualdad natural; la ce contrarrestar la dificultad de acceso a los estudios universitarios por razones económicas y materiales por parte de los estudiantes. Empiézase, pues, por la ayuda a los más necesitados, por medio de becas que, a veces, no sólo abarcan los gastos de matricula, sino incluso los de alojamiento en Colegios Mayores, etc.

Martín-Retortillo aboga por que, así como el Munic:pio, representado por el Ayuntamiento, tiene atenciones que cumplir, cuales son, por ejemplo: alcantarillado, alumbrado, sanidad, etc., así, igualmente, con un aumento de subvenciones, debe asumir la obligación de facilitar estudios univers'tarios a aquellos vecinos que lo precisen, significando esto, sin duda, una labor educacional y social que a los Ayuntamientos compete.

En fin, el problema de ayuda a un versitarios, no debe concretarse inicamente al campo estatal, sino que debe establecerse una verdadera cooperación municipal para. la resolución definitiva del mismo.

R. S. S.

\section{Boletin de la Sociedad Castello- nense de Cultura}

Castellón de la Plana.

Abril-jun:o 1957. T. XXXIII, C. II.

Extracto: Jaime I y Castellón (J. Sánchez Adell).-Estudio histórico-juridice 
de la Albufera de Valencia y de sus aprovechamientos (S. Salcedo Ferrándiz).

\section{Estudio histórico-juridico de lo Albufera de Valencia y de sus aprovechamientos, por S. Salcedo Ferrándiz.}

Ferrándiz examina en ésta, su tercera exposición, el problema cuyo título se indica, estudiando detenidamente el problema histórico -desde la Baja Edad Media hasta nuestros días-; de cada uno de los aprovechamientos que se obtienen del lago. Ocúpase, especialmente, del problema piscicola, como aprovechamiento tradicional del mismo. Cita el privilegio otorgado en Morella, en 1250, por el rey D. Jaime I, que autoriza la pesca en el lago a toda persona, sin más limitaciones que la de pagar como tributo la quinta parte de lo pescado (el aquints), cuyo cobro era contratado con el aArren cador del qu ntow o aCredenceiros.

Existen las Comunidades de Pescadores, reguladas desde los tiempos del rey D. Jaime. El funcionamiento y costumbres de la Comunidad de El Palmaro, considerada como la más venerable muestra de la organización-gremial española, son expuestos con todo detalle en este artículo.

Igualmente estudia el funcionamiento de las de aCatarrojan y aSillan, como instituciones muy similares a aquélla.

Se ocupa de los problemas planteados con la promulgación de la Ley de Pesca de 1942 y de su Reglamento del siguiente año, así como del Anteproyecto para una reglamentación especial.

Noś cita la regulación histórica de da pesca con caña en aEl Perelló y la pesca de la anguila.

Habla, asimismo, de la cinegética en la Albufera, cuyo aprovechamiento es considerado hoy como el que más 'sareado interés rinde al propietario del lago, el Ayuntam ento de Valencia. Este, actualmente arrienda este aprovechamientc mediante subasta que se celebra en la Casa Consistorial.

Trata de otros aprovechamientos secundarios, cuales son: el de las plantas tipicamente acuát caş (cañas, juncos, etc.), $\boldsymbol{y}$ el de los animales (ranas, gambas, etc.). Se ocupa de la riqueza arrozal en la zona fronteriza a la Albufera y de la de los terrenos ganados a ésta, dando por term nado su artículo con el no menos interesante estudio del aprove- chamiento turistico que él califica de cen potencias, debido a lo mucho que queda por hacer en cuanto a lo relacionado con este problema.

R. S. S.

\section{Revista de Estudios Extremeños}

\author{
Badajoz.
}

1955.

Núms. 1-4.

Extracto: Crónica del Monasterio de Guadalupe (Fr. A. Barrado Manzano). El hallazgo de la lápida de troserpina, de Mérida (J. Alvarez Sáenz de Buruaga). - Privilegios concedidos a Montemolin (H. Mota Arévalo).

\section{Privilegios concedidos a Montemolin,} por H. Mota Arévalo.

Lns privilegios concedidos a Montemolin por el Rey Don Alfonso X el Sabio en 1282, según la copia mecanográfica sacada en $19 \overline{0} 6$ por el señor Mota Arévalo del pergamino que contene el Privilegio Real existente en el Archivo de dicho Ayuntamiento, son los siguientes:

1. Que sean reales para siempre.

2. Del Concejo de Sevilla.

3. Que nunca torne en poderio de la Orden de Santiago ni de otra alguna.

4. Que se juzguen por los mismos Fueros que los de Sevilla.

5. Confirmación de sus términos.

6. Que guarden la señal (sello) de Montemolin.

7. Que no se haga justicia en todo el término, sino en la Villa.

8. Mercado ferial todos los domingos.

9. Que aquellos que vinieren al citado mercado estén libres de impuestos.

10. Que el que sea osado de ir contra este privilegio o parte de él, que pague al Rey diez mil maravedis de la moneda nueva y a los moradores de la Villa todo el daño doblado.

Estos privilegios, en fin, fueron otorgados a Montemolín, por el Rey Sabio. apor la lealtad que manifestaron siguiéndole cuando el Maestre y los Freires de la Orden de Caballeria de Santiago se alzaron contra éls.

R. S. S. 


\section{c) REVISTAS JURIDICAS Y POLITICAS}

\section{Anuario de Desecho Civil}

Madrid.

Enero-marzo 1857. Tomo X, fasc. 1.

Extracto: El arbitraje del Consulado de la Lonja de Valencia y la vigente Ley de Arbitraje (V. Fairén). - La propiedad vista a través de los clásicos agustinos españoles del siglo $\mathrm{xvr}$ (B. Difernan).-La renuncia liberatoria del comunero (J. Roca).-Aspectos rećientes del Derecho civil francés (D. Tallón).

\section{Pretor}

Madr:d.

Abril 1957

Nủm. 56.

Extracto: Las profesiones Jiberales en la Ley de Arrendamientos Urbanos (B. Attard Alonso).- La acción revisora del precio del subarriendo en la nueva Ley de Arrendamientos Urbanos (J. Molla).

Mayo 1957.

Núm. 57.

Extracto: Obras de conservación y mejora en el arrendamiento urbano (M. López).

\section{Revista Critica de Dere- cho Inmobiliario}

Madrid.

Marzo-abril 1957.

Núms. 346-347.

Extracto: Los derechos reales administrat:vos (J. González Pérez).-Temas hipotecarios: La legitimación del derecho inscrito ( $R$. Chinchilla).-Concentración parcelaria. Problemas (I. Delgado).-Bases para la construcción del método de la Ciencia del Derecho (P. Gimeno).

\section{Los derechos reales administrativos, por} Jesús González Férez.

El catedrático de Derecho administrativo de la Universidad de La Laguna actualiza con este trabajo el problema de los derechos reales administrativos, cuya figura, si bien fué observada por varios tratadistas a princip os del siglo, con Hauriou se precisa la misma, al indicar que se estaba en presencia de un auténtico derecho.real cuaiedo aludia al grupo de derechos especiales conferidos por la Administración sobre el dominio público (concesiones).

Si con posterioridad a la primera década del siglo actual surgió una polémica en los principales paises del continente sobre la nueva categoria jurídica, en la que participaron tratadistas españoles e hispano-americanos, el señor González Pérez orienta este trabajo para examinar la posible admisión de esta figura de derechos reales en el campo administrativo, y, al efecto, critica algunas objeciones que, por un prurito de autonomia científica, miran con recelo todo concepto elaborado en el seno del Derecho privado.

Tras de analizar el concepto de derecho real, y en cuanto a la naturaleza. jurídica de los mismos, distingue cuándo son administrativos, en los que existe, frente al titular del derecho real administrativo, un sujeto cualificado, investido de prerrogat:va, titular del dominio.

Aun cuando es difícil la clasificación de los derechos reales que examina, distingue los derechos de goce, de uso, de disfrute, los que implican consumo de la cosa y los derechos de adquisción, y señala entre estos últimos los de tanteo y retracto.

En el desarrollo de su trabajo estudia lo relativo a los sujetos, objeto y contenido de los derechos reales administrativos, y finaliza esta interesante aportación exponiendo cuanto afecta al nacimiento, comercio jurídico y ext'nción de los mismos; es decir, el aspecto dinámico de aquéllos, y señala como causas de su nacimiento la Ley, la concesión y la prescripción.

Con respecto al comercio juridico, indica que el hecho de que el dom nio público esté excluido o sustraido al tráfico jurídico ordinario no impide que los derechos reales reconocidos sobre el mismo puedan ser objeto de los negocios juridicos típicos del Derecho civil, y al tratar de la extinción distingue respecto 
del titular del derecho real administrativo y respecto de la Administración, y dentro de este concepto, por incumplimiento del concesionario o por exigirlo el interés público.

En relación con el objeto, los modos o causas de extinción que enumera son: por desaparición de la cosa y por desafectación, señalando otra relativa al título de constitución, toda vez que cesan al vencimiento del plazo fijado en el título mencionado, plazo variable en la legislación admin strativa.

La clara exposición del tema y el rigor cientifico que a todo lo largo de este trabajo pone el autor acrecientan la utilidad e importancia del tema tratado.

S. S. N.

\section{Revista de Administración Pública}

\section{Madrid}

Mayo-agosto 1956.

Núm. 20.

Extracto: La morfologia del poder político y la burocracia (J. Fueyo Alvarez).-Tendencias actuales en relación con el perfeccionamiento de las categorias superiores de la función pública (F. Garrido Falla). - La doctrina de los actos propios y el sistema de la lesividad (E. García Enterria).-Jurisprudencia.-Crónica administrativa. - Biblografía.

Tendencias actuales en relación con el perfeccionamiento de las categorias superiores de la función pública, por F. Garrido Falla.

El profesor Garrido Falla, al comenzar su interesante trabajo cuyo título encabeza este breve comentario, se formula la pregunta de si existe o no una clase superior de funcionarios públicos, estimando que la estructura jerárquica de la Administración pública determ na evidentemente la situación supra ordenada de unos funcionarios respecto de otros, $y$, por consiguiente, la posibilidad de considerar una clase superior; pero a continuación añade Garrido Falla que lo que interesa es saber hasta qué punto la función pública que corresponde a los grados elevados de la jerarquia administrativa está en manos de un conjunto de personas que, por la homogeneidad en cuanto al modo de su reclutamiento, en cuanto a su preparación intelectual $y$ profesional y en cuanto-si se quierea) espiritu de que está animada, constituye una autént ca cclase directivas.

Estudia con todo detalle este problema en el Derecho comparado, principalmente en las legislaciones inglesa, alemana, italiana y francesa, para analizar luego la carrera administrativa en España tal como está regulada por la legislación vigente.

Tras de las, consideraciones que acabamos de exponer en sintesis a nuestros lectores, entra el profesor Garrido Falla en el estudio de lo que, a su juicio, debe consistir el perfecc:onamiento de los funcionarios, admitiendo la posibilidad de diversas especies, que estima son las si'guientes:

1.2 Perfeccionamiento de los funcionarios directivos que acaban de entrar al servicio de la Administración pública mediante el sistema de la oposición.

2. Perfeccionam ento de los funciorarios administrativos de categorías inferiores que los habilite para el ascenso a la categoria superior.

3.8 Perfeccionamiento de los funcionarios que vienen ya prestando sus servicios en la categoría directiva de la Administración públican.

A continuación estudia con detalle cada uno de estos apartados y después de agotar realmente la materia, examina con gran detenimiento la organización de las enseñanzas con los problemas que se derivan de los establecimientos encargados de las mismas, los alumnos y los métodos de trabajo. En cuanto a los establecimientos de enseñanza, considera que es de gran importancia la misión de la Universidad, y opina que es necesario proyectar una reforma conjunta y coordinada de las Facultades de Derecho y de Ciencias Politicas, Económicas y Comerciales. Después de analizar el artículo 14 del Reglamento de 7 de septiembre de 1918, afirma que no existe en España ningún Centro que con carácter general tenga por finalidad el perfeccionamiento de los funcionarios. Ahora bien, destaca que son numerosos los ejemplos que actualmente tenemos en nuestra Patria de Escuelas Especiales para determinados Cuerpos: la Judicial, la Diplomática y la General de Folicia, etc., poniendo de relieve. por su carácter más general, como dirigido a la formación de los funcionarios de la Administración local, la Escuela 
Nacional de Adm:nistración y Estudios Urbanos, integrada en el Instituto de Estudios de Administración Local.

En relación concretamente con los cursos de perfeccionamiento para la clase directiva, Garrido Falla considera como puntos básicos para su organizac:ón los siguientes:

1. El montaje de estos cursos debe ser la consecuencia de un plan de cooperación entre la Administración y la Universidad. Aunque ésta es una cuestión que sólo las circunstancias de cada - pais pueden determinar, dicha cooperación puede incluso hacer innecesaria la construcción de un edificio particularmente destinado a ser la sede de la Es. cuela, pues pueden bastar las aulas universitarias.

2. ${ }^{\circ}$ Stpuesto lo anterior, no parece necesario (aunque aquí también son las circunstancias las que deben aconsejar) la creación de una Escuela permanente de perfeccionamiento, pues que parece suficiente la consecución de los fines propuestos con la simple organización de «Cursos» de perfeccionamiento cuya frecuencia y caracteristicas habrán de determinarse de acucrdo con las necesidades.

3. $\mathrm{La}$ cooperación aludida con la Universidad puede servir de base a una organización descentralizada de los cursos que pueden desarrollarse precisamente alrededor de las distintas Universidades del pais.

4.0 Administrativamente, la cuestión debe estar encomendada a los propios órganos que en cada Administración nacional asumen la competencia específica sobre da cuestión de los funcionar:os públicos. Se ha de lamentar que en España no exista una Dirección General de la función pública -análoga a los similares organismos existentes en otros paises- que centralice y unifique la politica funcionarials.

El trabajo termina con un interesante estud:o sobre los alumnos y métodos de trabajo a seguir.

\section{A. D. P.}

\section{Revista de Deresho Mercantil}

Madrid.

Znero-marzo 1357.

NúE. 63.

Extracto: Los auxiuiares del comersiante en Derecho espar̃ol (E. Borra- jo). - La irreivindicabilidad de los titulos al portador y su denuncia como sustraidos o extraviados (B. Pellisé). Ias indicaciones de procedencia en los productos (C. E. Mascareñas).-Fynorama del Derecho mercantil italiano (G. Santini).

\section{Revista de Derecho Procesal}

\section{Madrid.}

Año 1957.

Núm. .1.

Extracto: Las ideas directrices del proceso en la sintes.s de un escritor sudamericano (E. Allorio). - Nuevas reflexiones sobre el juicio jurídico ( $F$. Carnelutti).-Ideas y textos sobre el principio de publicidad del proceso (V. Fairen Guillén).-Objeto y forma de la reconvención en el Derecho español (L. Prieto Castro).-El tema de da competencia territorial en conciliación (L. Prieto Castro).-Extinción de la servidumbre de paso, innecesaria (F. Rodríguez Valcárcel).-La jurisdicción contencioso-administrativa y las cuestiones penales (J. Pérez González).

La jurisdicción contencioso-administraliva y las cuestiones penales, por Jeșús González Pérez.

Aun reconociendo la especialidad de la jurisdicción contencioso - administrativa, examina el autor el problema de cuándo se está en presencia de una cuestión penal o administrativa, teniendo en cuenta que si en el ejercicio de la función administrativa pueden imponerse sanciones, a veces de gravedad considerable, ello pone de relieve, dada la extensión cada dia más amplia de la potestad de la Administración en esta materia. que existen conexiones que hacen dificil la fijac:ón de fronteras entre estos sectores del ordenamiento público, delimitándose en este trabajo dos cuestiones fundamentales: 1.0 Cuándo se está en presencia de una sanción penal o administrativa impuesta por el Estado, y $2 .^{\circ} \mathrm{A}$ guién corresponde la potestad sancionadora cuando un mismo hecho es corisiderado a la vez del.to $y$ falta adminisirativa.

Planteado asi el problema, si el principio general se traduce en que si se está ante una sanción penal la Administración carece de potestad para conccer el he- 
cho, comoquiera que para la aplicación de ciertas leyes se establece una jurisdicción distinta, como, por ejemplo, Guerra, Marina, las Autoridades administrativas; etc., el autor expone un criterio diferencial que resume asi: En principio, a la jurisdicción ord.naria, a través del correspondiente proceso, corresponderá la imposición de la pena. Cuando por alguna ley se atribuya el conocimiento del hecho delictivo a alguna jurisdicción espec.al, corresponderá a esta jurisdicción, y cuando se está en presencia de una sanción administrativa, su conocimiento corresponderá a la Administración.

Corroborando sus puntos de vista, inserta abundante jurisprudencia que revela la doctr.na nuantenida por la misma en la materia objeto de estudio, e indica que en los supuestos de doble sanción, cuando no juega el principio de independencia del procedimiento, como el mismo acto no puede ser juzgado y casti- gado dos veces, las reglas a tener en cuenta son: 1.a Tienen preferencia los Tribunales, pues el Código penal ha de prevalecer sobre las disposiciones admiristrativas. 2.a $\mathrm{Si}$ los particulares acuden al Juzgado denunciando el hecho, no puede admitirse la interposición de la Administración para hacer cesar a la autoridad judicial en sus actuaciones, pues aquélla pudo perseguirlo de oficio y no lo hizo, y. en tal caso corresponde a! particular la elección de jur:sdicción ; y 3.a Perseguido el hecho por el Juzgado, no puede serlo después por la Administración; pero si fuera ésta quien sancionare la falta, su actuación no impediria la uiterior del Juzgado, según la doctrina jurisprudencial.

S. S. N.

\section{Revista de Estudios Politicos}

Madrid.

Nov.-dic. 1956.

Núm. 90.

Extracto: El concepto de la Teoria general del Estado y el problema del Estado de Derecho (E. Von Hippel). Las posibilidades del hombre en una civilización industrial (D. Rops).-Tendencias recientes en el Gob erno central británico (D. N. Chester).-Pro- blemas de politica militar: La guerra y el sentir político (F. L. Borreu).La Sociologia de las relig:ones en España (M. Lizcano).-r untual:zaciones en torno al 73 ( $R$. Ol.var).-Las nacionalizaciones inglesas en su aspecto politico (A. Serrano). - La realidad iberoamericana (A. Carro).

Tendencias recientes en el Gobierno central británico, por D. N. Chester.

El autor da cuenta de la evolución de la Administración británica a partir del año 1918, en la que destaca el aumento de funciones del Gobierno central, paralelo a la variación ocurrida en el carácter de aquéllas, cuyos aspectos característicos han sido: la imprec sión, en cuanto a la distinción de la actividad pública y privada; la actitud del público frente al individuo y frente al Gob erno, y la tendencia de los Departamentos centrales en asumir tareas que implican relaciones con un gran número de individuos de todo el país.

A este respecto se pregunta qué repercusiones han producido el acrecentamiento de las funciones y estos cambos en su carácter sobre la estructura y la actividad de la Administración británica. Su efectividad ha sido tan grande que $D$. N. Chester, en este trabajo, estudia las consecuencias y problemas originados, distinguiendo :

1. Aumento de volumen $\mathrm{y}$ número de Departamentos.

2. Desenvolvimiento de muchas clases nuevas de funcionarios, especialmente en el terreno científico y profesional, que se eleva a 75.000 personas, y que ha dado lugar a varios problemas.

3. Mayor cuidado de su preparación y reclutamiento y estudio del mecanismo gubernamental. En este aspecto considera especialmente la Administración, indicando lo relativo a la ampliación de los métodos de selección anteriores a la guerra, con la reserva de una proporción de las nuevas vacantes anuales para concurso restring:do dentro de los funcionarios civiles.

4. Cambios en las relaciones entre los. Ministros y funcionarios públicos, por una parte, y entre el : Parlamento $y$ el público, por otra.

Si en 1914 el Departamento de Correos y los negociados de Aduanas y Consumos y de Rentas Públicas eran los predominantes, en la actualidad la pirámide 
departameistal se his ampliado con otros Departamentos, zстесенtandose igualmente el número de funcionarıos. Asi, en Asuntos Lxteriores, de 190 pasó a 5.710, y el de Interior, de 770 a 3.740 . Al mismo tiempo también ha taioicio cambios en el sistema cie Gabinete, y como consecuencia de la mayor extensión y complej dad del Gobierno, existe un interdependencia más acentuada entre los distintos Departamentos.

Señala más adelante los distintos métodos de selecćión de los funcionarios, y termina con el estudio de la responsabilidad min.sterial y la fiscalización parlamentaria, en el que señala algunas innovaciones.

Resume su trabajo el autor destacando que el rasgo más notable del sistema uritánico de Administración pública en los pasados cuarenta años es el modo con que tan eficazmente ha respondido a todas las nuevas y varadas exigencias que se le han hecho.

S. S. N.

\section{d) REVISTAS DE HACIENDA $Y$ ECONOMIA}

\section{Impuestos de la Hacienda Pública}

Madrid:

Abril 1957.

Núm. 167.

Extracto: El mercado común europeo. Las reservas internacionales en -1956.E1 sistema fiscal suizo (J. F. Martí Basterrechea).-El contribuyente ante la Administración: normas sobre defraudación y reincidencia. - El funcionario y la funcón (J. López Nieves). Contabilidad superior de empresas ( $P$. Romero Cuadra). - Los presupuestos municipales en Francia.

\section{Recaudación y Apremios}

Madrid.

Enero-febrero 1957. Núms. 108-109.

Extracto: Reorganización de la Administración Central del Estado-I.a reforma de la Ley de lo ContenciosoAdministrativo (M. Segura).
Marzo 19z̄7. Sium. i10.

Extracto: La adjudicación de fincas a la Hacienda. - Defraudación y reincidencia: aclaración de ambos conceptos fiscales.

e) REVISTAS DE TRABAFO
Y SOCIOLOGIA

Revista de Estudios Agro-sociales

Madrid.

Oct.-dic. 1956.

Núm. 17.

Extracto: La aparcería y el trabajo agrícola (M. Hernainz).-Fomento de las zonas rurales. Los pueblos incomunicados (C. Martín-Retort.llo). Trabajadores españoles en el cultivo del arroz en Francia (A. E. P.).Nuevos salarios para las actividades agrícolas y ganaderas. (A. E. P.).

Fomento de las zonas rurales. Los pueblos incomunicados, por Cirilo MartinRetortillo.

Todo el trabajo del autor tiende a destacar la situación de Jos núcleos rurales, y aboga por ellos al objeto de que se eleve la s.tuación ambiental de los mismos mediante posibles mejoras, deteniéndose especialmente en cuanto a los medios de comunicación se refiere.

Primeramente manifiesta que la actual Ley de Régimen local se caracteriza por la rigidez y uniformidad de sus preceptos, y para determinadas materias ha sido preciso dar normas de excepción, sobre todo cuando afectan a las grandes ciudades, citando algunas de aquéllas, y agrega que en los Municipios rurales hay particularidades espec alisimas que no pueden estar previstas en el texto de la Ley, lo que exige también normas especiales. A su parecer, hubiera sido más lógico dictar una norma amplia en la que los Municipios rurales fuesen relevados de la aplicación de la homogeneidad, y mediante la misma pudieran resolver las situaciones exrepcionales que se dan en ellos por su marcada especialidad. 
En el ciesarrollo de su exposicion destaca la penuria y protección de algunos pueblos, que la literatura captó, para indicar que hay que llevar a ellos la mejora y elevación moral y económica de sus vecinos.

Seguidamente trata del remedio, y cita párrafos del Fuero del Trabajo y algunos pensamientos de Joaquin Costa, cuando decia que para remediar esos males era preciso escuela y despensan, aclarando el contenido de ambos términos.

Refiriéndose a la modernización de las carreteras, indica que éstas deben ir paralelamente a un plan de trascendencia social y, a estos efectos, destaca la labor que realiza el Instituto Nacional de Colonización, recordando, a su vez, párrafos del a Informe sobre la Ley agrarias de Jovellanos. Después, resume la legislación en esta materia y señala las obligaciones de las Diputaciones provinciales, sin que a pesar de esto -agrega-, el Estado deba prescindir de su colaboración, cooperando mediante le ejecución directa de las obras o facilitando la realización de las mismas, bien por los pueblos, o por las mancomunidades de ellos.

Alude también, el autor, a la Ley de Carreteras de 1877, en la que se establecía que la construcción se podia realizar por particulares o compañías mediante concesiones, actualizando las normas en vigor sobre la materia objeto de su estudio y resumen su critërio, para estos fines, en una coordinación de recursos de los órganos estatales.

Termina manifestando que la incomunicación supone una falta de solidar dad $y$ que es necesario un plan de comunicaciones que ponga término a esta situación para incorporar a una vida mejor a los pueblos aislados.

\section{S. S. N.}

\section{Revista Internacional de Sociología}

Madr:d.

Enero-marzo 1956.

Núm. 53.

Extracto: Bosquejo de una historia de la Sociología (L. von Wiese).-El problema de la integración social de los trabajadores y las relaciones humanas
(P. Lucas Verdú).-Cristianismo social (S. Minguijón).-El sentido mistico de las artes plásticas mayas (C. A. Echanove). - La mortalidad en el segundo año de la vida en España (A. Arbelo).

\section{g') OTRAS REVISTAS}

\section{Anales de la Universidad de Murcia}

Murcia.

Curso 195556.

Núms. 1-2.

Extracto: Desviación de poder (E. Mastínez Useros).-La colisión de derechos (J. López Berenguer).-La festividad de San M guel como término y plazo del negocio juridico (J. Barthe Porcel).

\section{Desviación. de poder, por E. Martínez Useros.}

Comienza este autor definiendo el concepto de edesviación de poder», según e: formulado por Hauriou. Defínido el mismo, cabe aducir que, atiende esta doctrna a la garantía de la más pulcra juridicidad y al fomento de la moralización de la actividad administrativa, en favor de los intereses colectivos y de los administradoss. Cont núa tratando de la arevisión jurisdiccional de la actividad administrativas, haciendo una detallada exposición del problema en el período anterior al Estado de Derecho y en éste.

En el tercer capítulo se ocupa de la ajurisdicción administrativan, señalando el criterio doctrinal que califica la jurisdicc ón administrativa como la que se ejercita por jueces especiales sobre litigios concernientes a relaciones públicas, sin que se llegue con este concepto a la esencia misma de la jurisdicc ón administrativa; dedica especial alusión al estudio de este problema, tal como es en6ocado por el profesor Duguit, no sin dejar de entrar en el estudio de las tesis expuestas por Garbagnati, Barthélemy, Otto Mayer, Jellinek, Guicciardi y, entre nosotros. Garrido Falla. Da un concepto de ajurisdicción contencioso-admiristrativa $\mathbf{v}$ dice que. únicamente con esta amplitud estimativa de la esencia de la misma, es dado mantener un crite- 
sio unitario de ella, que permita inciuir en la jurisdicción contencioso-administrativa el acervo de los recursos por exceso de poders, problema especitico éste del que se ocupa en el capitulo siguiente.

Apunta que este recurso (exceso de poder), históricamente nació por segregación del jerárquico, que adoptaba forma contenciosa.

Siguiendo a Laferrière, nos da un concepto constitutivo de la adesviación de podero, estudiando la causa y motivos del acto.

Expone la desviación de poder, y la discrecionalidad, incompetencia e ilegadad, terminando su trabajo con la problemática objetiva de la desviación de poder, con la determinación del fin de la norma y la determinación y revisabilidad de los motivos del agente.

R. S. S.

\section{Boletin de la Universidad de Granada}

Granada.

1955.

Tomo IV.

Extracto: Progreso económico y organización económica $(\mathrm{J}$. Alvarez de Cienfuegos).-Dos incunables jurídicos en la Biblioteca Universitaria de Granada (J. Moreno Casado).-Elementos de cultura popular en el Este de Granada (W. Giese).

\section{Revista de la Universidad de Madrid}

Madrid.

1956.

Núm. 18.

Extracto: La reconstrucción de San Sebastián (1814-1820). (M. Artola).La educación cientifica (E. Jimeno).

1958.

Núm. 19.

Extracto: La energía termonuclear, ¿será susceptible de aplicaciones pacificas? (J. Balta Elías).-Semblanza de un rey carlista en las páginas de su aDiarios intimo (C. Seco).

\section{b) EXTRANJERO:}

\section{Revista Internacional de Ciencias Administrativas}

Bruselas.

$19 \overline{7}$.

Núm. 1.

El Director de la Revista, Pierre Seeldrayers, presenta en el editorial que encabeza esta nueva confección de la Revista, estimando que espera, tal como está presentada, satisfará sobremanera la mayor parte de las reivindicaciones de la mayoria de sus lectores.

La nueva Revista es resultado de la fusión de la antigua Revista Internacional de Ciencias Administrativas y del Boletin Progreso en la Administración Pública y la nueva Revista constará en adelante de tres ediciones unilingües, en español, francés e inglés, respectivamente, esperando que tal esfuerzo sea apreciado en su nuevo valor y permita la realización de una mayor difusión de intercambio de ideas e informaciones en el campo de actuación del Instituto.

El reciente Congreso de Ciencias Administrativas, celebrado en Madrid, en septiembre pasado, adoptó acuerdo para la publicación de Revista en que el español figure como idioma utilizado. Comenzará con artículos de doctrina, que tratarán todos los aspectos y tendencias de los teóricos y prácticos de las ciencias administrat:vas. A partir de ahora, algunos artículos serán traducciones, cada vez que las mismas emanen de autores que los hayan pensado y escrito en su lengua propia, pero diferente de cualquiera de los idiomas de trabajo del Instituto. Por regla general los artículos serán originales, aunque se reproduzcan algunos estudios que huberan sido publicados en Boletines o Revistas de difusión limitada. Tras la parte doctrinal aparece la información bibliográfica en tres formas diferentes, recensiones, breves not:cias de libros y monografias bibliográficas. ILa fuente de tales recensiones será la información biblingráfica del Boletín Progreso en la Administración Pública. Por el contrario, las noticias de libros serán la continuacón de ls obra bibliográfica comenzada en la ya antigua Revista. En la medida de lo posible se lamará la atención de los 
autores de las noticias bibliográficas hac.a el interés de presentarlas al mismo tiempo en forma analitica y critica.

Las monografias bibliográficas son resultado de largo $y$ paciente trabajo de formación de ficheros bibliográficos del Instituto. Mlediante la difusión de monografias bibliográficas sobre los más variados temas, los ficlieros importantísimos del Instituto Internacional de Ciencias Administrativas, se ponen por partes a disposición de los lectores de la Revista y se divulgan en escala internacional. Otra parte de la Revista contiene informaciones y noticias, entre las que figuran en primer lugar las más atinentes a prácticas y realizaciones llevadas a cabo en diversos paises, refiriéndose, tanto a situaciones de hecho, como a las de derecho.

Las noticias breves son exclusivamente informaciones de hecho, con el fin de asegurar en escala internacional la presentación de las principales actividades de actualidad en todos aquellos que se interesan por las ciencias administrativas.

La crónica del Instituto es medio especializado de información para los miembros del mismo, sobre las actividades llevadas a cabo por el Instituto de que forman parte, destacando las realizaciones esenciales. La Revista seguirá siendo trimestral, constando de tres ediciones en español, francés e inglés, respectivamente, y se adjuntarán resúmenes relativamente detallados en el idioma de la edic:ón. Se seguirá realizando esfuerzo para conseguir la publicación de recensiones bibliográficas breves en cada uno de los mencionados idiomas.

Representa todo ello un gran esfuerzo del Instituto y de la Dirección de la Revista, ut:lísima para cuantos se dedican ai estudio de las ciencias administrativas en su nuevo formato y contenido.

\section{J. G. M.}

La organización en las Ciencias administrativas en España, por Luis Jordana de Pozas.

Indica el autor que el trabajo tiene por objeto presentar en sintesis el cuadro general de la organización de las ciencias administrativas en España, remitiendo al lector al número 2. 1956, de la a Revue Internationale des Sciencess Administratives», dedicado integramente a España, y a las bibliografías de González Pérez, Boquera Oliver y Guayta, $y$ la publicada en $195 \bar{j}$ por el propio autor de este trabajo.

Iníciase éste con algunos datos geográficos, estadísticos e históricos relativos a España, señalando que el áres del territorio peninsular $e$ islas acyaqentes es de כ003.54ð kilómetros cuadrados, presentando extrema variedad en altitud, clima, fertilidad y orografia. La población crece incesantemente, y desde el primer censo de población, efectuado en 1857, el incremento ha sido del 82 por 100. A fines de 1956 la población era de 29.202 .785 habitantes, calculándose que la cifra de 30 millones será alcanzada antes de 1960 . La densidad media de población por kilómetro cuadrado, con diferencias enormes: 16 en la provincia de Teruel y 284 en la de Barcelona. Existen 9.214 Munic:pios, de los que más de 6.000 tiene población inferior a 2.000 habitantes, 54 más de 50.000 y tres más de. $\mathbf{5 0 0 . 0 0 0}$.

La unidad racial, religiosa y de sentimientos de la población española es verdaderamente notable. Aunque jurídicamente la unidad política data de hace unos cuatrocientos años, España llegó a su unidad nacional al unirse en matrimonio los Reyes Católicos, Fernando de Aragón e Isabel de Castilla, considerándose se logró la unidad en 1492. Durante el antiguo régimen la Administración civil estaba prácticamente delegada por el Rey en los Consejos. Desde la Edad Media la Monarquía llevó a cabo acción constante de unificación y centralización. En el siglo xIX, hasta la Constitución de 1876, la historia española es suces:ón rápida y pendular de regímenes políticos contrarios.

Tras el fracaso de la primera República; España fué gobernada alternativamente por dos partidos políticos, y desde el punto de vista técnico, Jas leyes administrativas de este período son excelentes. En general predomina la influencia francesa. ILa pérdida de las Antillas (1898) determinó crisis polít:ca y económica, y a partir de entonces la función pública está basada cada vez más en el mérito. Hay tendencia a la descentralización administrativa en favor de la Administración local, y se practicia frecuen. temente la personificación de servicios públicos, obteniendo ciertas tendencias administrativas, asentimiento general, procurándose el perfeccionamiento administrativo y contencioso bajo la protec- 
ción de los derechos e intereses de los admin.strados.

La actual constitución politica del Estado español se contiene en las leyes fundamentales de Sucesión del Jefe dei Estado, Ley 2id julio 1947; Fuero de Jos Españoles, Ley 18 julio 1945; Fuero del 'Trabajo, Ley 9 marzo 1938 ; Creación de las Cortes Españolas, Ley 17 julıo 1942; Ley del Reteréndum, 22 octubre 1445, sólo derogables o modificadas por acuerdo de las Cortes y referéndum popular.

Espana, comunidad politica, es un Estado católico, social y representativo, que se constituye en Reino. La preparación y elaboración de jas lcyes pertenece a las Cortes; su sanción, al Jefe del Estado. Por razón de urgencia o tiempo de guerra, se admiten decretos-leyes, que deben comunicarse a las Cortes. A éstas puede devolver el Jefo del Estado, para nuevo estudio, leyes aprobadas.

Las Cortes son Asamblea de Procuradores natos y electivos. Los primeros, en número reducido, y los segindos, designados por Ayuntamientos, Diputaciones provinciales, Colegios de profesiones liberales, Cámaras de Comercio, Sindicatos, las Academias e Instituciones de investigación científica. El Jele del Estado nombra 50 Procuradores. La representación de las Administraciones locales, Sindicatos y Corporaciones forman la mayoria de los miembros de las Cortes. La función judicial pertenece exclusivamente a los Jueces y Tribunales; la ejecutiva, al Gobierno, formado por el Jefe del Estado y los Ministros. Los derechos, deberes y garantia de los españoles, están contenidos en el Fuero de los Españoles, que proclama el respeto a la dignidad, integridad y libertad de lo persona humana, la igualdad ante la ley, la admisión a las funciones públicas, li seguridad jurídica y derechos de los españoles.

Como fuentes del Derecho administrativo figuran las leyes, las disposiciones generales aprobadas por decreto $\mathbf{u}$ orden, estatutos y ordenanzas de las administraciones locales, y en el ámbito local, la costumbre. En las leyes diferéncianse las fundamentales, las ordinarias, los decretos-leyes y las leyes de bases.

La administración directa del Estado se conoce con el nombre de Administración central; las demás administraciones territoriales forman la I.ocal. Lis establecimientos públicos, scrvicios personificados y Corporaciones de dereche pú- blico integran la categoría variada de Administraciones institucionalea.

Los Departamentos minisreizies han de ser creados por una ley. Ultimamente existían los de Asuntos Exteriores, Gobernación, Ejército, Marina, Aire, Justicia, Hacienda, Agricultura, Éucación Nacional, Obras Fúblicas, Tr.ıvajo, Información y Turismo, Comer.io, Industria y Presidencia del Gobier:o (1).

La representación del Gobierno corresponde, en las provincias, a los Gobernadores civiles, y en los Municipıs, con excepción de los que son capitales de provincia, a los Alcaldes. La I ey de Régimen local rob.sstece la autoridad de los Gobernadores. Hay órganos colegiados de carácter corsultivo. El más importante es el Consejo de E.stadc.

El territorio nacional está dividido en Provincias, y éstas, en Municipios y Partidos judiciales. Hay 50 - Provincias, 9.214 Municipios y 600 Distritos judiciales. La división municipal es producto de evolución histórica.

Es hecho constante en la historia política española que cada cambio de régimen ha sido seguido de una nueva Ley de Administración local. El Derecho administrativo local suele ser más moderno y representa un grado más avanzado en la evolución del Derecho general. La nueva Ley de Administración local fué preparada con la colaboración del Instituto de Estudios de Administración Local y del Consejo de Estado, y constituye un Código de más de 2.500 artículos, que ha introducido muchas innovaciones importantes. Entre ellas, las concernientes a la Administración pública, contratación administrativa, municipalización de servicios, servicios sociales y culturales, urbanismo, responsabilidad de las Administraciones, modos de gestión, sistemas de recursos $y$ otras.

LLas Provincias están definidas por la Ley como Mancomunidades de Municipios. Los Ayuntamientos están formados por representantes elegidos por jefes de familia y por los Sindicatos, y de ellos, en la elección de segundo grado, sale la designación de los miembros de las Diputaciones provinciales. Hay una autoridad individual nombrada por el Gob:erno o sus delegados y un Consejo elegido.

(1) Recientemente se ha modificado. creandose el Ministerio de la Vivienda. 
Hasta comienzos dé sig.o $u x$ el Derecho aciminisirativo español repartió la competencia entre los diversos órganos del sistema a tres esferas administrativas: Estado, Provincia y Municipio, divid.éndose los asuntos en sectores, cada no de los cuales se atribuia con carácter exclusivo a la Administración central, a la provincial o a la municipal. Ejemplo, la policia, la instrucción pública, la sanidad, beneficencia, carreteras, puertos, etc. La nueva Ley de Administración local no habla de competencia exclusiva, sino de que la competencia municipal no sérá obstáculo de prestación de servicios análogos atribuidos por las leyes al Estado o la. Provincia. Ua competencia de los órganos ocales rigue siendo muy amplia, refiriéndose al gobierno y administración de ios intereses peculiares de los pueblos, al fomento $y$ satisfacc.ón de las necesidacies generales, y de aspiraciones dè ia comunidad nacional. La enumeración de fines en la Lc) no es limitativa. La U.ey regula la municipalización y provincialización de serv cios. Hay predominio de órganos individuales, si bien, se reserva a. los coleg:ados las decisiones de mayor trascendencia.

En materia de bienes, han sido derogadas las desamortizadoras del siglo XIX, tratándose de favı recer. Ia reconstrucción de los patrimonios comunales.

A partir de 1924 el régimen de tutela Be configuró como situación excepcional trasitoria, rigiendo un sistemia de autonomia, siendo los actos y acuerdos de autoridades y Corporaciones locales ejecutivos, susceptibles de recurso ante los Tribunales de lo contencioso-administrativo. La Ley establece con amplitud la responsabilidad civil directa o subsidiaria de las Entidades locales, incluso los daños con ocasión del funcionamiento de los servicios públicos o del ejeucicio de atribuciones sin culpa o negligencia graves imputables personalmente a sus autoridades, funcionarios $o$ agentes. Sin embargo, el principio de autonomía está limitadu por la minuciosidad de las disposiciones legales y reglamentarias, por el carácter gubernativo del nombramiento de los Alcaldes y Presidentes de las D:putaciones provinciales, por el carácter nacional de los Cuerpos de Secretarios. Interventores y Depositarios de Administración Local. por el control del Ministerio de Hacienda en el examen de presupuestos, ordenanzas de exaccio- ries y otros actos, por la inspección de la gestión económica.

La legislación de Régimen local tiene carácter de uniformidad atenunda por cl régimen posible de Carta, por la subsistencia de algunas costumbres $o$ instituciones, por el régimen de las dos provincias de Canarias y las de Navarra y Alava, por los llamados pueblos adoptados por el Jefe del Estado, Ley de 13 de junio de 1940, para reconstruir localidades gravemente dañadas durante la guerra civil, por la existen ia de Mancomunidades o Agrupaciones de Municipios y Entidades locales menores.

Varias leyes a partir de 1344, han regulado de modo semejante, pero no idéntico, el desarrollo urbano de las grandes ciudades.

La Administración institucional tiene larga tradición en España $y$ ha ido surgiendo te manera empirica en los más diferentes campos de actividad. La estructura de esta clase de entidades suele ser representativa y encarnar en órganos designados o elegidos en todo o parte por los mismos interesados.

Hay servicios dotados de organización personificada y autónoma, como el $\mathrm{Pa}$ trimonio Nacional, el Forestal del Estado, el Instituto Nacional de la V vienda, el de Colonización, etc. El volumen de inversiones realizadas por estas Entidades, ha necesitado corrientemente impulsos de frenar el fenómeno y regular el control público y funcionamiento, gestión $e$ inversiones de dichas Entidades. De ahí la legislación sobre cajas especiales, principalmente las leyes de 5 de noviembre de 1940 y 13 de marzo de 1943.

No hay una estadistica oficial de funcionarios públicos que puede calcularse, entre funcionarios civiles y militares, en dos por ciento del censo de población de 1350 .

Cuatro etapas pueden recordarse en cuanto a normas que han regido en la función pública en España. El antiguo régimen, en que la selección se llevaba a cabo discrecionalmente, habiendo la costumbre llegado a crear una estabilidad de hecho. En una segunda etapa aumenta el número, y un gran estadista, Bravo Murillo, luchó por establecer una ley de empleados públicos, que aunque no fué lograda, sí sirvió para hueva etapa, Real Decreto 18 de julio de 1852. regulando el ingreso basado en el mérito con sistemas de ascensos èn varios turnos, abriéndose la cuarta etapa 
en los últimos años del siglo xix, con tendencia a constituir Cuerpos especiales regidos por disposición orgánica, verdadero estatuto de cada uno de ellos, declarándose expresamente la inamovilidad. Esta cuarta etapa llega hasta nuestros dias, anunciándose reforma administrativa que signifique nueva ordenación de la función pública. El procedimiento es único, el ingreso es la oposición. El ascenso se realiza por lo común por antigüedad, las retribuciones son más bajas que las similares de carácter libre, hay derechos de jubilación y de pensión, $y$ en cuanto a los funcionarios de Administración local, su reglamentación es mucho más completa y moderna que la de la Administración general. Existe para los Cuerpos nacionales la Escuela de Administración Local, con cursos de perfeccionamiento, estando las carreras administrativas locales cuidadosamente reguladas y garantidos los derechos $y$ deberes. Los funcionarios de Organismos autónomos o Administraciones institucionales están regidos por Estatutos - Reglamentos basados en el sistema del mérito, asegurando condiciones frecuentemente superiores a las que prevalecen en la Administración del Estado.

La reforma administrativa equivale en el orden administrativo, a lo que la reforma constitucional supone en el orden político. La reforma fundamental de la Administración venia impuesta por el cambio político de los años 1836-1939. $\mathrm{Ha}$ constituído una de las tareas preferentes de las Cortes y Gobierno, y se ha llevado a cabo mediante una serie de leyes orgánicas, entre las que cabe mencionar la de 30 de enero de 1948; Consejo de Estado de 25 de noviembre de 1944 ; Tribunal de Cuentas 3 de diciembre de 1953; Organización sindical 26 de enero, 6 diciembre 1940; Expropiación forzosa, 16 diciembre 1954; texto único de Régimen local, 24 junio 1055; Jurisdicción contencioso - administrativa, 22 diciembre 1956 ; Sanidad, 25 noviembre 1944 ; Industria, 24 noviembre 1939 ; Educación primaria, 17 julio 1915; media y profesional, 16 julio 1049 ; superior, 29 julio 1943 , etc. Se han creado en varios Departamentos ministeriales Secretarías Técnicas. El Decreio-ley. de 20 de diciembre de 1956 , la crea en la Presidencia del Gobierno, como órgano de estudio y documentación, asistencia técnica, cooruinación para la reforma $y$ perfeccionamiento de la organización y actividad administratives.
En cuanto a las ciencias administrativas en España, la exposición doctrinal de la materia se inicia en la Politica para Corregidores y Señores de vasallos en tiempo de paz y de guerra, 1587, por Castillo de Bovadilla. En la primera mitad del siglo xix predominan los estudios de Administración sobre los de Derecho administrativo. Se crea en Madrid la Escuela de Administración y, posteriormente, en la Facultad de Derecho, una sección de Administración. Colme:ro aparece como gran figura, publicando la primera edición de su Tratáo de Derecho administrativo en 1850. En la nueva etapa la enseñanza es juridica, con influencias francesa, alemana e italiana. En 1918 se produjo una reacción en sentido nacional, despertándose el interés hacia los autores y problemas españoles, con un mayor conocimiento de las tendencias de. Inglaterra y Estados Unidos. Se crea la Unión de Municipios y en 1924 la Escuela de Adminiztración Local, por la Diputación provincial de Barcelona, y a raíz de la guerra de $1936-39$, se operó cambio muy significativo, pues además de la antigua facultad de Derecho, se creó la de Ciencias Politicas, Administrativas y Comerciales, se aumentó a dos el número de cursos de Derecho administrativo. En los estudios del Doctorado pueden comprenderse uno o varios de los estudios superiores de Derecho asministrativo. En la nueva Facultad, se estudia, no sólo la teoría general del Derecho administrativo, sino principios de ciencia de la administración, organización administrativa y servicios públicos, historia de las instituciones políticas y administrativas, teoría de la política, régimen político de la administración, organización y economía de Marruecos y Colonias, organ zación política y administrativa internacional. Existen, además, el Instituto de Estudios de Administración ILocal, la Escuela Judicial, la Diplomática y la de Policia.

En el orden internacional, la participación en Congresos e Institutos fué bastante continua (actuación del Profesor Gascón y Marín).

Constituido el Instituto de España, en é! figuran las Academias de Ciencias M'orales y Políticas y la de Jurisprudencia y Legislación. En 15\% se creó el Iristituto de Estudios Políticos con su Sección de Administración, publicando la Revista de Estudios Politicos \& tc de Aominiätración Púbies, que han uicar- 
zado prestigio intertaciona'. En 24 de noviembre de $\mathbf{1 0 3 6}$ se fundj el Consejo Superior de Investigaciones Cientificas, con sus Institut's de Francisco Vitor:a, Balmes, de Sociologia, Nacional de Estudios Juridicos, Patronato José Maria Cuadrado, y Estudios e Investigaciones Locales, con bibliotecas especializadas, becas, premios y publicaciones. Por Ley de 6 de septienibre de 1940, se funda el Instituto de Estudios de Administración Local, con fines de investigación, estudio, enseñanza, formación y perfeccionamiento de gestores y empleados. Entre sus publicaciones se encuentran algunas de las mejores de nuestra bibliografia administrativa, y suya es también la Revista de Estudios de la Vida Local. El Instituto de Cultura Hispánica, creado en 1845, tiene departamentos de estudios y publicaciones relativas a la comunidad cultural hispánica. Cabe recordar también el Instituto de Estudios Agroso. ciales, el Nacional de. Estadistica, la participación en el Instituto Internacional de Ciencias Administrativas, la Comisión Nacional de Cooperación con la U. N. E. S. C. O., así como varias Asociaciones privadas, como la Española de Ciencias Administrativas, la de Ciencia Politica y la Asociación de Municipalistas Españoles.

\section{J. G. M:}

\section{Città di Milano}

Milán (Italia).

\section{Abril 1857. Año LXXIV, núm. 4}

Extracto: Las nuevas técnicas de organización, y las Admin straciones municipales (U. Genesio).-Problemas legislativos de la ordenación urbanistica intermunicipal (D. Rodella). $-\mathrm{La}$ industria de la goma en MJán (D. Ferrari).

\section{Problemas legislativos de la ordenación wrbanistica intermunicipal, por D. Re- della.}

En la vigente lègislación italiana sólo hay un precepto referente a los planes intermunicipales: el articulo 12 de la Ley de Urbanismo de 17 de agosto de 1942. Tal penuria normativa en esta materia concreta, ha originado una considerab'e confusión respecto a las caracteristicas de los planes intermunici-

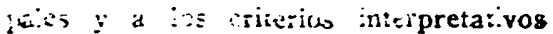
que deben scrles aplicadus.

¿i a-ticulista, apartindose de las tencicicias uniformistas que quieren encajar ia ordenación urbanistica de toda el territorio nacional en planes de tres grados d-stintos (uno, municipal; otro, intermunicipal; y otro regional), cree que la intermunicipalidad de un plan de ordenación constituye sólo un supuesto episódico que únicamente puede aparecer en dos casos: la ordenación de una gran ciudad, que exige la coordinada ordenación de los Municipios limítrofes; y la ordenación de Municipios colindantes, de análoga importancia, cuyos planes, por la situación geográfica, por sus caracteres comunes y por sus probleinas comunes, no pueden ser concebidos por separado. En todos los demás casos sí existirá, indudablemente, una sapeditación de los planes municipales a los regionales, pero no la necesidad de esa ordenación intermunic pal que cabria calificar como subregional.

¿La iniciativa de los planes intermunicipales debe partir de la autoridad gubernativa 0 de los Municipos interesados? ¿La definición del plan debe ser dejada a la voluntad de los Municipios o puede ser realizada por el Gobierno? Estos y otros problemas que surgen de los planes intermunicipales se han pretendido resolver por algunos autores invocando la analogia de estos planes con los territoriales, propugnando al efecto la aplicación de las normas vigentes para estos últimos. Pero el articulista discrepa de esas opiniones y cree que una solución eficaz sólo puede ser hallada a través de una reforma dc la Ley.

La reforma habria de partir de un criterio inicial completamente distinto del que informa actualmente el artículo 12 de la Ley de Urbanismo. Y tal criterio inicial debe fundarse en la constitución de una Agrupación forzosa de los Municipos interesados, Agrupación cuyos órganos serían los competentes para adoptar los acuerdos oportunos con la mayoria cualificada que se considerase conveniente exigir. Ello evitaria que la resistencia de un solo Municipio :mpidiese la formación del plan, y evitaria también las complejas tranitaciones de acuerdos, informes, etc., entre los Munic pios afectados.

Como conclusión de su artículo, Rodella resume la propuesta aprobada por el Consejo Nacional de Urbanismo de 
Turín, sintetizándola en las siguientes directrices:

1.a Determinar leg:slativamente, como se ha hecho con los planes municipales, el contenido de los planes intermunicipales, haciendo especial hincapié en el factor económico, de tal modo que la Agrupac ón sea autosuficiente, para lo cual habrán de existir en el plan zonas industriales.

2.2 Respetar la iniciativa de los Municipios, pero prever la obligator:edad de la Agrupación y la posibilidad de formar Consorcio con la Provincia.

3. La calificac ón de la mayoria puede ser diversi, según las circunstancias; para ello purden servir de orientación las normas de la Ley municipal y provincial sobre Mancomunidades y Agrupac ones, y la abundante jurisprudencia, en esta materia.

4. ${ }^{\text {a }}$ Prever una duración determinada, pues la intermunicipalidad puede ser mudable y no permanente.

5.a Valorar y calificar la intervención de los órganos descentralizados del Estado en materia urbanistica.

6. Extender a los planes intermunicipales las medidas de salvaguardia vigentes para los plaires municipales.

A. C. C.

Mayo 1957.

Año $\mathbb{L X X I V , ~ n u ́ m . ~} 5$.

Extracto: Sobre las licencias de habitablidad (D. Rodella).-Las nuevas técnicas de la organización y las Administraciones municipales (U. Genesio).

\section{L'Amministrazione locale}

Roma.

Diciembre 1956. Año XXXVI, núm. 12.

Extracto: El control de leg timidad del Prefecto en un nuevo proyecto de Ley (A. Gelpi).-Indagaciones sobre una futura reforma: el control regional sobre los actos administrativos de las Entidades locales (F. Spantigati).

E! control de legitimidad del Prefecto en un nuevo proyecto de Ley, por A. Gelpi.

Un proyecto de Ley del Gobierno italiano, pretende modificar las normas actualmente en vigor, relativas ${ }^{1}$ al control que el Prefecto ejerce sobre los acuerdos munic pales y provinciales.

En la evolución contemporánea de la legislación local en Italia, los principios de autarquía de las Entidades locales han estado frenados siempre por un control gubernativo ampl:o, más extenso que el habitual en otros paises, incluso e: nuestro. El texto de la Ley municipal y provincial italiana de 1934, establecia un control - tanto de legalidad como de méritos-, por parte del Prefecto, cuyo visado era indispensable para la eficacia de los acuerdos adoptados por las Corporaciones. Ese control, suspensivo de la eficacia de los acuerdos, fué transformado radicalmente por la Ley de 9 de junio de 1947, que lo conv'rtió en simple control represivo y limitó su alcance a.la legalidad de los acuerdos. En resumen, la citada Ley de 1947 conferia al Prefecto el poder de anular. - en el término de veinte días, a contar de la fecha en que le fueran notificados, aquellos acuerdos municipales que considerase ilegales; a tal efecto, todos los acuerdos debian serle enviados dentro de los ocho días siguientes a su adopción.

Pues bien, ahora, el proyecto de Ley formulado por el Gobierno italiano -aun manteniendo las caracteristicas sustanciales del control regulado por la Ley de 1947-, confiere al Prefecto la facultad de recabar. en cada caso, datos c elementos de juicio complementarios, cuando tenga dudas sobre la legitimidad de cualquier acuerdo que le haya sido notificado. lo que suspende el transcurso de los plazos. Ello, a juic:o del articalista. supone un retroceso en la evnlución de la autarquía local y representará. en muchos casos, una demora considerable en la ejecución de los acuerdos de las Corporaciones.

Termina Gelpi su articulo propugnando como solución una propuesta que en otra ncasión se habia formulado. para modificar los artículos 3.0 y 12 de la citada Ley de 1947 ; pronuesta que mantenía estrictamente la obligación de enviar al Prefecto todos los acuerdns adoptados, y confería a dicha Autoridad provincial la facultad de promover la anulación de los mismos, por legalidad. en el plazo de veinte dias, a contar desde da fecha de recepción del acuerdo. In- 
dudablemente, esta solución, teóricamente al menos, parece más respetuosa con ta autonomía municipal.

A. C. C.

Enero 1957. Año XXXVII, núm. 1.

Extracto: La asistencia por enfermedad a los pension stas (D. Cosi).-Indemnización a los gestores municipales $y$ provinciales (G. Turchi).-Tercer Congreso Nacional técnico de las Empresas munic:palizadas del gas.

Febrero 1957. Año XXXVII, núm. 2.

Extracto: Los Municipios y la, ejecución de obras públicas mediante pago diferido (A. Gelpi).-El ordenamiento administrativo de las Entidades locales en el territorio de la Región solicitada, con particular referencia al nuevo s:stema de control y a la naturaleza $y$ funciones de las Mancomunidades libres (G. Franchina).

\section{Nuova Rassegna di Legislazione, Dottrina e Giurisprudenza}

Florencia (Italia).

1 enero 1957. Año XIII, núm. 1.

Extracto: Modiflcaciones a la Ley munic pal y provincial en materia de controles: un primer comentario al dictamen y proyecto de Ley aprobado por la Comisión parlamentaria (G. Genoviva).-Ejecución de las sentencias que condenan a la Administración a la devcluc:ón de impuestos directos (G. Cirelli).-Reorganización de la Comisión central de Haciendas locales (A. Paolo Torri).

16 enero 1957. Año XIII, núm. 2

Extracto: Premisas a la reforma de la Administración: el público no es un enemigo (A. de Valles).-(Transcribe también el artículo publicado por Sebastián Martín Retortillo, en la Revista de Administración Pública sobre Una experiencia en materia de requisas: el caso La Piras).

] febrero 1957. Año XIII, núm. 3.

Fxtracto: Renuncias y dimisiones del Teniente de Alcalde y de otros gestores zunicipales y provinciales (E. Bertuzzi).-La simplificación de las formal dades burocráticas con vistas a la mayor agilidad de los servicios píblicos: una propuesta del Muricipio de Bolonia (G. Dozza).-Las resoleciones adoptadas por los terceros Es tados generales de los Municipios de Europa.

16 febrero $1957 . \quad$ Año XIII, núm. 4.

Extracto: Objetivos y finalidad de la municipalización en el d'scurso del Presidente de la COM. Achille Marazza.-El agitado problema de los tributos locales: la reforma de las Haciendas locales, y singularmente del impuesto de familia, según un proyecto de ley preparado por el Ministerio de Hacienda (D. Tossichetti).

Objetivos y finalidad de la municipalización, por A. Marazza.

En febrero del corriente año se celebró en Roma un Congreso de Alcaldes para examinar los actuales problemas de la munic:palización. Nuova Rassegnas recoge los párrafos más importantes del discurso pronunciado por Achille Marazza sobre los objetivos, finalidad, valor y ventajas de la municipalización. Nosotros hemos de limitarnos a ofrecer al dector una síntesis de los extremos de mayor interés abordados por el conferenciante.

Tras un preámbulo sobre el carácter de la municipalización y su valor politico-social, y un breve compendio de la historia del movimiento municipalizador, Marazza propugna una reafirmación legal de la facultad que tienen los Municipios de asumir aquellos servicios de interés relevante y actual para la comunidad, y critica la tendencia centralizadora y uniformista del Poder ejecutivo, cuyos controles representan un verdadero \&sabotajex -aunque involuntario-para las empresas munic:palizadas. Hace hincapié en que. la oposición frente al movimiento municipalizador deriva, más que del propio Estado, de los grupos industriales y de los intereses privados, cuyas podera sas presiones pesan -como opinión influyente- en la actitud de los órganos oficiales.

Para ilustrar sus afirmaciones con ejemplos concretos, expone las interferencias de la Administración central J 
de sus órganos periféricos en las farmacias municipales y en los transportes. Tal estado de cosas deriva -a su juicio-de la insuficiencia de la Ley actual sobre municipalización $y$, sobre todo, de la falta de directrices claras en esta materia por parte del Gobierno.

En vista de ello, $y$ aparte de otras gestiones de interés, se ha preparado por la Asociación un proyecto de ley cuyas directrices fundamentales son:

- reafirmar que son municipalizables todos los servicios que - no teniendo el carácter de función pública - revisten actualmente un interés de gran relieve para la colectividad;

- ampliar las facuitades de las empresas municipalizadas y su campo de acción, incluso mediante da expropiación de las empresas privadas que explotan servicios públicos, o mediante el rescate de las concesiones, o mediante derechos de prelación;

- regular mejor, según las nuevas exigencias de orden general y particular, la constitución $y$ el funcionamiento de los órganos de la empresa municipalizada;

- simplificar y disminuir los controles gubernativos, reduciendo al mínimo los de amériton.

Alude el orador al problema surgido $\epsilon_{3}$ estos últimos años con las centrales techeras. Todavía está formalmente en viэor la Ley de 1928 que altorizida a los Ainunicipios su instalación, perc les obligaba a conceder su gestión a Conscrcics Ce grupos económicos (agriculiores, incitstriales y comerciantes). Si en otros rectores de la alimentación se presertan problemas del:cados, en éste de la leche adquieren su máxima gravedad los aspectos higiénico y económico. Aun los paises dotados de elevada sentido de antodisciplina colectiva $\mathrm{e}$ individual, se aan visto obligados a reglamentar la disuribución de la leche en términos eminentemente intervencionistas (precios de orcducción y venta al público, márgenes romerciales, ef́c.), viniendo a convertir virtualmante su suministro en un servicio público monopolizado, al hacer imposible la concurrencia.

En general, es cierio nue no cabe desconocer las críticas contra los resultados -singuiarmente los económicos- obteanidos con la municipalización. Las empresas municipalizadas suelen tener un biance deficitario, pero el orador afirma yi: cá jérdida aparente es, en realifai, unz írmula qua expresa una iras- lación de gástos de los usuarios a los contribuyentes con fines sociales. Por otra parte, hay cargas impuestas - justificadamente o no- por el Estado que gravan considerablemente los presupuestos de las empresas municipalizadas. A titulo de ejemplo cita Marazza la carga sobre las empresas municipalizadas de transportes por pases gratuitos a d:versas categorias de personas (funcionarios, agentes de policía, mutilados, inválidos de guerra, etc.), carga que asciende a la muy respetable cifra de dos mil setecientos millones de liras anuales. Las empresas con déficit más voluminoso son las de transportes, que originan una situación delicadísima para las Haciendas 10cales respectivas. $Y$ el orador afirma que en muchos Municipios el balance deficitario sólo podrá ser soportado por el Estado; en otro caso, las empresas muricipalizadas deberán limitar su propia acción social o renunciar totalmente $\cdot \mathbf{a}$ ella, repercutiendo integramente sobre los usuarios el coste de los servicios. En otros términos, se planteará un problema de elevación de las tarifas.

Termina Marazza insistiendo en la función eminentemente económico-social que realizan las empresas municipalizadas, regulando indirectamente los precios er. los suministros o servicios de su órbita $y$ frenando con eficacia las iub:das y especulaciones.

\section{A. C. C.}

1 marzo 19.5i. Año XIII, núm. 5

Extracto: Aspectos particulares de la reforma de las Haciendas locales (V. Iazzari), - Exención del impuesto de familia sara las familias numerosas (A. Fedele).

16 marzo 1957.

Año XIII, núm. 6.

Extráto: Una experiencia de formación de los funcionarios en el cuadro de una reforma de ia Administración pública: la Escuela Nacional de Administración (4. Bcrdeau de Fontenay).-Sobre la autonomía fiacal del impuesto de familia (T. Mazzilli).

Una experiencia de formaciors de los funcionarios en el cuodro de suna reforma de la Admiristración píblica: la Escuela Nacional de Administraciśn, por H. Bordeau de Fontenay.

QNuova Rassegna..., recoge en sus pácinas d! texto de la cosierencie pronun.. 
ciada en 14 de febrero, er lá Cniversicac de Boionia, por el Director de la Escuela Nacional de Administración, de Francia. Orador de fácil y brillante páłabra, su conferencia mereceria ser reproducida también integramente aqui, por sus ideas claras y por sus calidades expresivas; pero en esta breve reseña hemos de ceñirnos obligadamente a los aspectos más sustanciales del tema fundamental tratado por M. Bordeau de Fontenay.

El punto de partida de la actual organización administrativa francesa, en materia de personal, se halla en la profunda reforma de 1945 . La reforma fué, primero, de estructura, y dividió en dos el escalafón superior que antes existia, para dar paso a dos nuevas carreras: la de cadministradores civiles, y la de esecretarios de Administración». Esta última carrera, después de diez años de vigencia, ha sido, a la vez, subdividida en dos: la de adjuntosn (traducimos provisionalmente por adjuntos la palabra francesa attachés) y la de asecretarios administrativoss.

Los eadministradores civiles》 (correspondientes a la administrative class inglesa) han de desempeñar los cargos de Vice-Director, Jefe de Servicio y Director, y tienen por misión adaptar la marcha de Jos asuntos adm nistrativos a la política general del Gobierno, preparar los proyectos de Ley o de Reglamento y las resoluciones ministeriales y trazar jas directrices pertinentes para su ejecución y para la coordinación de los servicios públicos.

ILos aadjuntos de la Administración y los esecretarios administrativos rresponden a la executive class inglesa, y tienen como misión-por su carácter de técnicos de la Administración-asegurar los trabajos de ejecución y algunas funciones especializadas (redacción, contabilidad, traducción). Los primeros entran a formar parte de la categoria A : los segundos, de la categoria B. La diferenciación entre unos y otros tiene por objeto evitar lo que el orador habia llamado, hace tiempo, confusión de competenciasy.

Otro aspecto fundamental de la reforma fué la creación de una Dirección General de la función pública, en el seno del Secretariado general del Gobierno, dependiente de la Tresidencia del Consejo; nuevo organismo encaminado a asegurar un minimo de unidad en la Administración y a corregir la excesiva independencia de los servicios. En la or. gäilización interna de esa Dirección $6 \in$ preveia, entre otros, un servicio de reciutamiento de funcionarios.

La formación y perfeccionamiento del funcionario merecieron preferente atención de los reformadores de 1945, que, convencidos de los defectos del antiguo sistema, concibieron uno más amplio, insp:rado en el logro de una formación completa (no estrictamente jurídica) y en un perfeccionamiento continuo. El nuevo sistema lo apoyaron en tres institucio. nes: los Institutos de Estud os políticos, la Escuela Nacional de Administración y e' Centro de altos estudios administrativos.

Los Institutos de estudios politicos (actualmente son siete) tienden a cubrir las lagunas de las Facultades de Derecho en lo relativo a la enseñanza de las ciencias sociales, administrativas y económicas. Dependientes de las Universidades respectivas, han de iniciar a los alumnos en los problemas concretos de la Administración y de la vida social, y pueden designar su profesorado entre personalidades ajenas a la Universidad (funcionarios civiles y militares y esper:ialistas competentes).

La Escuela Nacional de Administración, creada en 9 de octubre de 1945, tiene por objeto la formación de funcionarios para el Consejo de Estado, Tribunal de Cuentas, carrera d plomática y prefecticia, Inspección general de $\mathrm{Ha}$ cienda, Cuerpo de administradures civiless, etc. Sólo se admiten en la Escuela asp rantes jóvenes (edad máxima de veintiséis años para los titulados, y de treinta años para quienes ya son funcionarios), mediante exámenes en que el candidato ha de acreditar ampl a cultura general, conocimiento profundo de la tvolución general de las ideás y hechos politicos, económicos o sociales a partir de mediados del siglo xvil, y preparación especial en Derecho público, polít:ca económica y - según las seccionesen materias aún más especializadas. La Escuela comprende cuatro Secciones (Administración general, económica, f:nanciera, social y asuntos exteriores) a las que son adscritos los alumnos según le selección de los exámenes de ingreso. Una vez admitido, y mientrás cursa sus estudios en la Escuela, cada alumno disfruta de una dotac:ón que actualmente es (para ei alumno solte $: 0$ ) de 55.000 francos mensuales.

La duración teórica de los cursos es 
de tres años; en la práctica, por razones económicas, esa durac:ón es más reducida. aunque manteniendo su estructura de tres cursos.

El primer curso, de anoviciados o cambientacións, coloca a los alumnos junto a altos func onarios, para que aquellos tomen contacto experimental con la Administración. El funcionario debe hacer a) alumno test go y partícipe de sus actividades, llevarlo en sus desplazamientos, confiarle sus secretos $y$, si es posible, delegar en él una parte - reducida- de sus atribuciones. Este curso de novic:ado, al enfrentar directamente al alumno con la realidad administrativa suele producirle un desconcierto que, en la realidad, es beneficioso y le sirve para medir su personalidad y sus aptitudes para el ejercicio de la función pública.

El segundo curso es de estudio. Los alumnos reciben cierto número de lecciones ex cathedra, para perfeccionar y completar sus conocimientos generales. y para sentar las bases de una espec alización, según la sección a que están adscritos. Pero la parte más importante en la actividad de este segundo curso está constituida por los trabajos que los alumnos realizan en pequeños grupos, segín la fórmula anglo-americana del aseminarios, en contacto con jóvenes profesores, estudiantes universitarios y funcionarios. Al término de este segundo curso, los alumnos que han realizado satisfactoramente sus trabajos comparecen en un examen de grado, calificado por una comisión de funcionarios pertenecientes a las ramas correspondientes de cada Sección. La conceptuación final. que permite determinar a qué carrera ha de ser adscrito cada alumno, se forma: la mitad, por la calificación obtenida en el examen de grado: una cuarta parte. por las notas del ségundo curso (el de estudios). y la otra cuarta parte, por las observaciones referentes al primer curso, de noviciado.

El tercer curso es ya de aaplicaciónn: dos primeros meses, de contacto con una empresa privada de carácter industrial o comercial (cada alumno queda adscr to junto a un dirigente de empresas, para anreciar directamente el mecanismo y la mentalidad del sector privado y lns nroblemas de sus relaciones con la Administración). y después ya un periodn de anrendizaie concreto. de t:po práctico. nrientado hacia la carrera en que ei alumno va a ingresar.

Por último, como tercera institución, el Centro de altos estud:os administra tivos, encaminado a completar la formación necesaria para el ejercicio de las funciones administrativas: la información de las cuestiones de actualidad, el estudio de problemas nuevos y el contacto con funcionarios de otras dependencias y servicios. Se ha querido, con ese Centro, asegurar el perfeccionamiento del funcionario en el curso de su carrera, en el momento en que ha de afrontar su ascenso a los más altos puestos de la Administración.

Entre otras consideraciones finales, concluye el orador su conferenc:a afirmando que una verdadera reforma de la función pública se obtiene mucho más seguramente a través de la formación $y$ perfeccionamiento de los hombres que la ejercen, que no mediante la modificación de las instituciones o de los regimenes.

A. C. C

1 abril 1957.

Año XIII, núm. 7.

Extracto: La legitimidad de la vigente reglamentación de los espectáculos, en el Derecho público y de policía (G. Renato). - Legitimidad constitucional de las Com:siones tributarias ( $T$. Mazzilli).

\section{Municipal Review}

\section{Londres.}

Abril 1957. Vol. XXVIII, No. 328.

Extracto: Ventajas de la madera nacional.-Planificación y redesenvolvimiento.-Alumbrado moderno.-Relaciones entre el Ministerio de Educación y las Autoridades locales encargadas de la enseñanza.-Los discos de gramófono forman parte del material de bibliotecas.-El Burgo de Hedon.

Relaciones entre el Ministerio de Educación y las Autoridades locales encargadas de la enseñanza.

Se emplea mucho la palabra «Sociedad. cuando se hab!a de las relaciones entre ei Ministerio de Educación y las auto$r$ :dades locales encargadas de la enseñanza y desde que se anrobó la Ley de Educación de 1944. el Ministerio se ha convertido en socin princinal. Sin embargo. es la autor dad local la aue se enfrenta con los problemas cotidianos 
que surgen, y por eso, soii elios los que pueden resolver estos problemas. Los informes presentados por estas autoridades reflejan más vivamente la realidad, ya que estos informes se redactan con datos obten:dos por ellos mismos y no remitidos, como sucede con los informes del Ministerio de Educación.

Mayo 1957. Vol. XXVIII, No. 320.

Extracto: El puerto de Southwold en el rio Blyth.- La ciudad de Peterbrough.-Lucha contra las ratas.-Modernización de los baños de Hammersmith.-Purificación de las aguas de Oxford.-Estadisticas sobre el coste del cuidado de los niños.

Estadisticas sobre el coste del cuidado de los niños.

El gasto total ocasionado por el mantenimiento de un niño en las distintas residencias del país, varía en cada Condado. El gasto más elevado es de chelines 219, mientras el más pequeño es de 77. Algunos Condados gastan sólo unos dos chelines para vestir al niño por semana.

\section{Public Service}

Londres

Abril 1957.

Vol. XXXI, No. 4.

Extracto: Los impuestos municipales suben.-El Libro Blanco para los Burgos de Condado.-La Magna Carta de IL:verpool.-Presidiendo las mesas electorales.-Se aprueba el aumento de pensiones del personal jubilado de fábricas de gas y electricidad.- Menos personal administrativo en las oficinas municipales inglesas.

Menos personal administrativo en las oficinas municipales inglesas.

Según el per:ódico aHull and Yorkshire Times", más de 120 empleados administrativos de la ciudad de Hull, han dejado sus colocaciones para trabajar en empresas privadas. A las convocatorias anunciadas para ocupar las vacantes que estos dejan, sólo se presentan una o dos personas, cuando antes de la guerra se hubieran presentado más de cien personas para cada uno de estos puestos.

\section{Rural District Review}

\section{Londres.}

Marzo 1957. Vol. LXIII, No. 8.

Extracto: Las nuevas propuestas financieras.-Concesiones por mejoras en viviendas. - Informe sobre Gales. Reorganización del Gobierno local.Los conductores de automóviles y la Ley.-El Gobierno local en otros países.

\section{Reorganización del Gobierno local.}

Las cinco Asociaciones de la Autoridad local han acordado aprobar el $\mathrm{L}_{\text {in }}$ bro Blanco que se ocupa de las zonas y situaciones de las autor:dades locales de Inglaterra y Gales. Entre las propuestas que aparecen en este Libro Blanco está la de solicitar que ciertas funciones ahora ejerc:das por los Consejos de Condado, sean ejercidas por los Consejos de Distrito de los Condados. También se solicita reduc:r el número de zonas muy pequeñas que todavía existen en el país. La Asociación se opone a que se fijen poblaciones mínimas.

Abril 1957. Vol. LXIII, No. 4.

Exrracto: Los Consejos parroquiales.Comentarios financieros.-Condiciones que debe reun:r el representante rural.-El bosque y los árboles.-La prensa local.-El Gobierno local en el extranjero.

\section{Comentarios financieros.}

Según las cifras que aparecen en este artículo vemos que el coste de una vivienda de tres hab:taciones en los distritos rurales es de 1.074 a 1.985 libras, para los años correspondientes a 1955 y 1956. Incluyendo el precio del terreno y los gastos generales, el precio total sería de unas $\mathbf{1 . 6 5 0}$ libras.

\section{Secretaries Chronicle}

Londres.

Marzo 1957. Vol. XXXIII, No. 8

Extracto: La Ley de Loterías de 1958. Crónicas sobre la historia de la adua. 


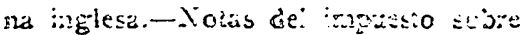
los ingresos.-Casos jurijicos de inrezés para los Secretarios murnicipales.-Casos juridicos de interés para los Administradores públicos.- ¿ P prede el presupuesto traernos la prosparidad? ¿ersinología económica y cuntercial.E! ercloso.-Sanidad.

\section{¿Puede el presupisesio traerios la fros- peridaci?}

[5: piesupuesto afecia a la prospericiad del pais en tres sentidos. En primer fugar, la afecta eccrómicariente, ya ose ce toma una decisión directa de la canAidá que se va a gastar del dinero nacisnal por el Esiado y la cantidad que so va a gastar por los partictilares. En seguido lugar, el presupuesto, determisa hasta cierto punto, la disiribacićn de jos ingresos del pais. $Y$ en tercer lugar, el presupuesio afecta psicológicamente a jos habitantes de! país, así como a los deudores y acreedores del extranjero.

Abril 185̈T. Vol. XXXIII, No. 4.

Escracto: El Juez de Paz.-Las películas en el mercado común.-Cusos juridicos de interés para los Secretarics.-Casos jurílicos de interés para ios Auministradores públicos. - Ias Calas in iustific: das a las reuniones dc: Ccásejo, tanîo del Alcalde como de los dr:ass mienioros de aquél.-Notas del impuesto sobre los ingresos.-Pcítica monetaria.-Función del secretario en una empresa moderna.- - ia copia de documentos.-Terminoilogía económica y comercial.-Estuá:o de las comunicaciones postales y telegráícas. Ias curreceras.

Las foltas iajisstificadas a las remmiones dét Conisejo, tanio del Alcalde como cie los c'einús mientoros de aquel.

$\mathrm{Si}$ cralquier miembro del Consejo falia duranîe un periodc consecutivc de ssis meses a las rcuriones, cesa aurométicamente como miembro de dicho Consejo. Por orra jerte, si si llicide cic sisalquier Burgo fuera de I.oncires, acse r.serte de su Burgo ie un: manesa soxtinda ciurante un espacio de tierngo -19ario a tos neses, salvo an coso be

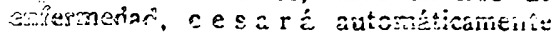
scre Alesio y el Conscjo no tiene fa-

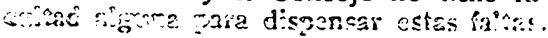

Hice C. G. F. Govente

ïonjres.

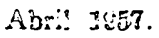

Vol. L, No. 4.

Érinazo: Inpecia que los hogares so desiagän. - Inziguración del nuevo edifcio paro el Ayuntamiento de Chežì:z Ccanty.-Desarroilo industrial de ivijford Haren.- La educación en Herto fordshire.

\section{La edsucoción en Herifordshire.}

Según informa el Comité escargado de la educación en el Condado de Fertfordshire habia unos 110.800 alumnos de enseñanza primaria y secundaria en este Condado en enero de 1957, mientras que estudiaban unos 33.000 for la nocine. El Condado cienta con 5 is escuelas para estos alumnos. Se calcula que para 1003 la cifra se elevará a 122.000. En los últimos diez años se han creado tres escuelas técnicas y sieqe de diversos tipos.

C. C. R.

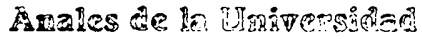 de Semis Doarditgo}

\section{Ciulad T:ujillo (Rẹública Dominicana).}

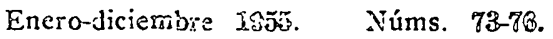

ExTracto: Instituciones Wrunicipales Españoias (B. Rull Villar).

Instizzciones Municipales Españolizs, por B. Rull Villar.

E! 28 cie enero de 1955 , en ei-Paraninio de la Universidad de Santo Dominro, $\epsilon !$ Dr. Ruil Villar, Alcalde de Vao Jercia, pronenció esta conferencia : CInstî́ciones Municipa es Españolas:. Sus p.imeras frases son de agrấexmiento

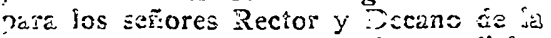

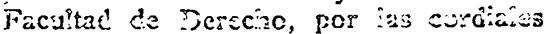

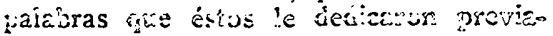
nente.

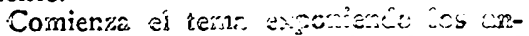

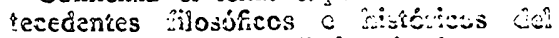

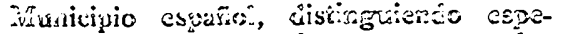
íamente le trifuencia romaria en 20

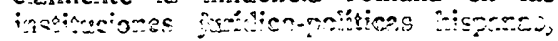


Se ias cusles, ia fundarental fué, prec:samerte, el Mun:cip:o. Trata del concepto de la Justicia en el Derecho romano $y$ del concepto igualitario de la misma en el hispano.

De la constitución del Municipio valenciano, se ocupa de forma destacáa. Hace historia del mismo desde el momento en que la ciudad fué conquistada por el Rey D. Jaime I de Aragón y, a este respecto, expone que dicho Rey organizó el Municipio valenciano con una similitud y una analogia muy grandes a la del Municipio romano. El Consejo municipal, que es el órgano multitudinario de la soberania del Municipio, tiene a su cargo la función leg.slativa orgánica conocida en la política europea, y en él se apunta la primera democracia El Municipio valenciano, dice, «influyó, por su peculiar constitución, en las nuevas orientaciones del Municipio españolo. Hace un estudio del mismo, según su actual os ganización, de acuerdo con las disposiciones contenidas en la Ley de Régimen local, y se detiene en la exposición del problema de la elección de sus componentes por tercios.

Termina su disertación con elocuentes palabras, que fueron muy aplaudidas, en las que expone que ael Municipio espafiol ha venido a adquirir su estructura orgánica definitiva $y$ ha venido igualmente a conservar los principios fundamentales de nuestro ideario, que han perfilado nuestra personalidad: Principio teológico, jurıdico y políticos.

\section{R. S. S.}

\section{Revista Municipal}

Santiago de Chile.

Enero-febrero 1957.

Núm. 8.

Extracto: Las Rentas municipales.-Estudio comparativo de la Administración municipal y de la Administración del Estado.-Actividades de la Conferencia Nacional de Municipalidades.La ciudad de Santiago en relación a las demás capitales.-Autonomía municipal.-Finanzas municipales.-Los Municipios norteamericanos.-Las Municipalidades frente al reajuste de los sueldos de la Administración pública.
Estisdio comparativo de ia idministración inissicipal y de is Adiniristración del Estado.

Con motivo de la desvaloraización ma netaria, las Mun:cipalidades chilenas han debido sufrir las consecuencias del proceso inflacionista, que ha afectado a la economia del Pais, durante los últimos años. Pạa darnos idea de cuál sea la situación presupuestaria de aquéllas frente a la del Estado, comparemos los porcentajes (contenidos en el cuadro que se inserta en el artículo que comentamos), y observemos cómo los presupuestos municipales han aumentado en menor proporción en relación con los aumentos que ha experimentado el presupuesto Fiscal.

Como consecuencia del problema planteado, se dictó, en 1945, una Ley, que tuvo por objeto reestructurar, tanto el sistema de ingresos como la escala de remuneraciones a los servidores municipales. Por Ley de 1950, se establece que a éstos se les pague una gratificación complementaria equivalente a siete veces la diferencia de sueldos, salarios, quinquenios, etc., $\sin$ otorgar un financiamiento adecuado. Es en 1952 , cuando se reconoce a los empleados y obreros municipales, el reajuste automático y anual de sus sueldos y salarios, de acuerdo con el alza del costo de la vida, mediante, eso sí, del otorgamiento de algunos pequeños ingresos a las Municipalidades. Estos ajustes son derogados por Ley de 1956, (Ley de Congelación), que establece un aumento de sueldos y salarios del 46 por 100 del alza del costo de la vida, sin indicar de dónde los Municipios obtendrán fondos para atender a este mayor gasto. La Conferencia de las Municipalidades superó una crisis económica al influir en la promulgación de la Ley de agosto del mismo año.

Otro de los problemas planteados en este articulo, es el de si existe o no excesiva burocracia municipal. Si se hace un estudio comparativo del número de empleados y obreros de las Municipalidades de Chile $(4.500$ y 9.500 respectivamente), con el de los funcionarios y obreros de la Administración central (187.025 y 30.386), la respuesta no necesita contestación.

En cuanto al problema de la retribución de los funcionarios municipales, se observa, cóno en un número aproximado a la cuarta parte de éstos, sus sueldos son inferiors al recesario vital, proble- 
ma aún más agudizado en lo que respecta a los obreros dependientes de la Administración municipal.

R. S. S.

\section{American Municipal News}

Washington.

28 febrero 1957. V́ol XXIl, No. 1.

Extracto: Las primeras cincuenta familias refugiadas húngaras se establemen en Wichita, Kansas.-Nuevo tratamiento de las aguas residuales.- Se está redactando un proyecto de ley para la creación de un Ministerio de Asuntos Urbanos.

Se está redactando un proyecto de ley para la creación de un Ministerio de A suntos Urbanos.

El Congreso de los Estados Unidos está preparando un proyecto de ley que cree el nuevo Ministerio de Asuntos Urbanos. Las Oficinas de la Vivienda y de la Financiación de la Vivienda que ahora dependen de dístintos Ministerios, pasarán a depender del nuevo Ministerio.

30 marzo 1957. Vol. XXII, No. 6.

Extracto: El derecho que tienen las ciudades de anexionarse los suburbios. El planteamiento como clave del crecimiento urbano.-La ciudad de Nashville en Tennessee gana el premio de la aciudad más amplia de los Estados Unidos».

\section{El derecho que tienen las cirdades de anexionarse los suburbios.}

En una conferencia pronunciada por el Director de Webb \& Knapp, empresa encargada del desarrollo urbano, ha dicho que las ciudades tienen perfecto derecho a anexionarse sus suburbios, aun cuando éstos se opongan a esta medida. Opina que como los suburbios no pueden vivir sin las ciudades, pertenecen a éstas. No cree que esta medida sea antidemocrática, y si alguien viola los derechos democráticos son precisamente los suburbios, ya que no comparten las cargas municipales. No está bien que disfruten de los museos y parques de las ciudades y no contribuyan a los gastos de su mantenimiento.

\section{The United States Municipal News}

Washington.

28 febrero 1957.

Vol. 24, núm. 4.

Extracto: Seguro contra inundaciones. Viviendas.-La ciudad de Houston se anexiona más de 180 millas cuadradas con 102.900 habitantes. ¿Resultan caros los suburbios?-ILos policias femeninos del tráfico son tan competentes como pueden ser los hombres.

Los policias femeninos del tráfico son tan competentes como puedan ser los hombres.

Después de prestar servicio durante cinco años en la ciudad de Fresno, California, se ha informado de la eficiencia de los policías femeninos, que al parecer son tan eficaces como puedan ser los hombres. Como la función "de estos policias se limita a dirigir el tráfico y hacer cumplir las Ordenanzas de aparcamiento, esto deja libres a los policias masculinos para dedicarse a otras funciones.

15 marzo 1957.

Vol. 24. Núm. 5.

Extracto: El redesenvolvimiento urbano.-Delincuencia juvenil.-Defensa pasiva.-Empleo de coches patrulla con un solo policía para las capitales con más de $\mathbf{4 0 0 . 0 0 0}$ habitantes. Varias ciudades consideran la posibilidad de que el curso escolar sea de doce meses.Aumentan los costes de las carreteras.

\section{Delincuencia juvenil.}

El Ministerio de Sanidad, Educación y Bienestar ha presentado un proyecto de ley al Congreso solicitando fondos para llevar a cabo las sugerencias del Presidente de la Nación en cuanto a la lucha contra la delincuencia juvenil. El proyecto de ley autorizaria la concesión de ayuda económica a los Estados y ciudades que se ocupen de este problema. 


\section{Otras publicaciones recibidas}

Administración local abulenses, núm. 18. Aragón,, núm. 242.

- Barcelonas, núms. 26 y 27.

eBsbliogratia Hispánican, núms. 2 y 3.

* Boletin Circular del Colegio Oficial de Secretarios, Interventores y Depositarios de Administración Local de Castellón de la Hlanas, núms. 39 y 40.

-Boletın de Divulgación Socialı, números 125 al 127 .

-Boletin de Estadísticas, núms, 147 y 148.

* Boletin de Información del Excelentisimo Ayuntamiento de Carballinos, núms. ว0 al ว2.

- Boletín de Información del Ministerio de Justiciad, núms. 370 al 374.

- Boletin de Información local de Jaraiz de la Veras, núms. 32 y 33.

Bolctin de Información municipal de Argentonas, núm. 9.

- Boletín de Información municipal de Badajoz», núm. 4.

- Boletin de Información municipal de Chucenas, núm. 9.

-Boletin de Información municipal de Estepa», núms. 27 y 28.

- Boletin de Información municipal de Geronas, núm. 16.

-Boletín de Información municipal de La Bañeza», núms. 17 y 18.

- Boletín de Información municipal de La Pueblas, núms. 91 al 94.

- Boletín de Información municipal de Orensen, núm. 5.

-Boletín de Información municipal de Oviedos, núm. 20.

Boletín de Información municipal de San Feliú de Codinas», núm. 2.

- Boletín de Información municipal de Sevillaw, núms. 201 al 204.

- Boletin de Información municipal de Valencià, núm. del $4 .^{\circ}$ trimestre 1956.

-Boletín de Información municipal de Vall de Uxós, núms. 43 y 44.

- Boletín de la Comunidad de la Ciudad y Tierra de Segovian, núm. 656.

- Boletín del Ayuntamiento de Madrid», núms. 3.120 al 3.127 .

- Boletín del Colegio Oficial de Directores de Bandas de Música Civiles», número 143.

- Boletín Informativo del Colegio Oficial de Secretarios, Interventores y Depositarios de Administración Local de Albacetes, núm. 6.

-Boletín Informativo y de Orientación profesional de Salamancas, núm. 17.
CBoletir mensual Climatológico del Servicio Meteoróógico de la Livision de Tetuanx, numerus de enoro y tevrero.

- Boletin mensual Cl.matolog،cu del servicio Meteorológico raciunais, nuiseros 9 y 10.

- Boletin municipal de Coria del Rios, número de marzo.

- Boletin municipal de San Feliú de Lla bregat,, nums. 39 y 40.

«oletun municipal de Valdepeñas», nú meros 26 y 27.

- Boletin Oficial de la Zona Norte de Marruecoss, núms. 13 al 19.

- Boletin Oficial del Ministerio de Haciendas, núms. 2 al 5.

campon, núms. 180 y 181.

- Caza y Pescas, nums. 172 y 173.

cC. N. S.v, núm. 103.

- Circular informativa del Colegio Oficial de Secretarios, Interventores $y$ Depositarios de Administracion Local de Almerian, núm. 12.

- Circular informativa del Colegio Oficial de Secretarios, Interventores $y$. Depositarios de Administración Local de Huescad, núms. 35 y 36.

- Circular informativa del Colegio Oficial de Secretarios, Interventores y Depositarios de Administración Local de Vizcayax, núms. 31 y 32.

cuadernos Hispanoamericanosn, números 86 y 87.

Economiaø, núms. 680 al 683.

Economia Mundial, núms. 849 al $\$ 556$.

España Económican, núms. 3.059 al 3.065.

Gaceta municipal de Barcelonas, números 11 al 18.

-Guías, núms. 840 al 842 .

đGuipúzcoa Económica», núms. $172 \mathrm{y}$ 173.

-Hinor», núm. 30.

- Hispanian, núms. 64 y 65.

Indice Cultural español», núms. $13 \overline{5}$ y 136.

*Industria», núms. 173 y 174.

anformación Comercial Españolas, números 252 y $2 S 4$.

Información municipal de San Justo Desverns, num. 1.

Insulas, núms. 123 y 124.

Investigacións, núms. 344 у 345.

-Lacianax, núms. 12 y 13.

- La Voz del Municipio de Nervan, número 16.

aI.inares, nums. 69 y 70.

- Mejoran, núm. 23.

«Nuestro Colegion. núms. 44 y 45.

QPolicia», nims. 179 y 1 190.

«Razón y Fè, núms. 711 y 712. 
- Resumen Estadistico del Ayuntamiento de Madrid», núms. 189 y 190.

\& Revista de Ideas Estéticas», núm. 57.

- Revista de la Escuela de Estudios penitenciarios», núm. 126.

-Revista de la Hemeroteca Nacional, núms. 42 y 43.

- Revista general de Iegislación y Jurisprudencias, núms. 2 y 3.

aRevista general de Marina", número de marzo.

Revista Iberoamericana de Seguridad social», núm. 6.

Tiempo Nuevov, núms. 31 al 34 .

-Ubedax, núms. 87 y 88.
Aggiornamenti Socialiw, núm. 4.

«Boletín de Gerencia Administrativas, núms. 58 y 58.

Boletin Informativo de la Embajada del Japónx, núms. 6 al 8.

a Boletín Informativo del Ministerio de Hacienda de Venezuelas, núm. 125.

- Bulletin analytique de Documentation Politique, Economique et Sociale contemporainex, núms. 8 y 10.

«Capitoliums, núm. 4.

-Génova Statísticax, núm. 12.

- La Vie Urbaine», núm. 1.

Revue Politique des Idées et des Institutions», núms. 4 al 7 .

ACABA DE APARECER:

\section{FIANZA COLECTIYA Y MANCOMUNADA DE LOS DEPOSITARIOS DE FONDOS DE ADMINISTHACION LOCAL}

(Antecedentes históricos y legales sobre las fianzas y estudio sobre un proyecto de fianza colectiva y obligatoria de los Depositarios de Fondos de Administración Local)

por

\section{PRANCISCO RUIZ FERNANDEZ}

Abogado e Intendente Mcrcantil. De los Cuerpos de Interventores

y Depositarios de Administración Local

NOTA PRELIMINAR

por

CARLOS RUIZ DEL CASTILLO Y CATALAN DE OCON Director del Instituto de Estudios de Administración Local

Un libro de interés excepcional para los Depositarios de Fondos de Administración Local especialmente, en el que, con una documentación exhaustiva, se señalan las formulas que podrian existir para la constitucion de la fianza de aquellos funcionarios y que hoy representa un problema de extraordinaria dificultad.

Un volumen. Precio: 45 pesetas.

Pedidos a la Sección de Publicaciones del

INSTITUTO DE ESTUDIOS DE ADMINISTRACION LOCAL

J. Garcia Morato, 7.-Madrid 